Revista Ítalo-Española de Derecho Procesal

Vol. 2 | $202189-124$ pp.

Madrid, 2021

DOI: $10.37417 /$ rivitsproc/697

Marcial Pons Ediciones Jurídicas y Sociales

(C) Fredie Didier Jr.

(C) Hermes Zaneti Jr.

(C) Rafael Alexandria de Oliveira ISSN: $2605-5244$

Recibido: 02/11/2020 | Aceptado: 03/10/2021

Editado bajo licencia Creative Commons Attribution 4.0 International License.

\title{
ELEMENTOS PARA UNA TEORÍA DEL PROCESO ESTRUCTURAL APLICADO AL PROCESO CIVIL BRASILEÑO*
}

\author{
ELEMENTS FOR A THEORY OF THE STRUCTURAL PROCESS \\ APPLIED TO BRAZILIAN LAW
}

Fredie DIDIER JR.

Maestro en Derecho por la UFBA. Doctor en Derecho por la PUC/SP. Libre-docente por la USP. Posdoctorado por la Universidad de Lisboa.

Profesor asociado de la Universidad Federal de Bahía, en los cursos de pregrado, maestría y doctorado. Miembro de la Asociación Internacional de Derecho Procesal, del Instituto

\footnotetext{
* Este artículo constituye, en gran medida, una revisión del entendimiento expresado por los autores en el artículo "Notas sobre las decisiones estructurantes", que comprende la colección Procesos estructurales, organizada por Sérgio Cruz Arenhart y Marco Félix Jobim, publicada por la Editora Juspodivm (Salvador), actualmente en su 2. ${ }^{a}$ edición (2019), y que también fue publicado en Civil Procedure Review, v. 8, n. 1, 2017 (www.civilprocedurereview.com). La revisión, con refinamiento analítico, de nuestra compre nsión y el avance doctrinario brasileño sobre el tema fueron las razones que nos motivaron a reescribir ese artículo.

Este artículo es también el resultado del Grupo de Investigación “Transformaciones en las Teorías sobre el Proceso y el Derecho Procesal” vinculado a la Universidad Federal de Bahía, y del Grupo de Investigación "Fundamentos del Proceso Civil Contemporáneo" vinculado a la Universidad Federal de Espíritu Santo, ambos registrados en el Directorio Nacional de Grupos de Investigación del CNPq respectivamente en las direcciones dgp.cnpq.br/dgp/espelhogrupo/7958378616800053 y dgp.cnpq.br/dgp/ espelhogrupo/0258496297445429. El Grupo de Investigación Fundamentos del Proceso Civil Contemporáneo (FPCC) es financiado por la FAPES - Fundación de Amparo a la Investigación e Innovación del Estado de Espírito Santo, siendo esta obra un vehículo de divulgación de las informaciones e investigaciones hechas por el Grupo con relación al Caso Samarco (Desastre del Río Doce). Ambos grupos son miembros fundadores del "ProcNet - Red Internacional de Investigación sobre Justicia Civil y Proceso Contemporáneo” (http://laprocon.ufes.br/rede-de-pesquisa).

Tradução para a língua espanhola por Brian Ragas e José Angel Cornielles.
} 
Iberoamericano de Derecho Procesal, del Instituto Brasileño de Derecho Procesal y de la Asociación Norte e Nordeste de Profesores de Proceso. Abogado y consultor jurídico.

Hermes ZANETI JR.

Maestro y Doctor (UFRGS). Doctor (Università degli Studi di Roma Tre). Posdoctorado en la Università degli Studi di Torino.

Profesor del Programa de Posgrado Stricto Sensu de la UFES (Maestría).

Miembro de la Asociación Internacional de Derecho Procesal, del Instituto Iberoamericano de Derecho Procesal y del Instituto Brasileño de Derecho Procesal. Fiscal en el Estado de Espírito Santo.

\section{Rafael AleXandria de OliveIRA}

Maestro en Derecho Público (UFBA).

Especialista en Derecho Procesal Civil (Fac. Jorge Amado/JusPodivm). Miembro de la Asociación Norte y Nordeste de Profesores de Proceso (ANNEP). Procurador del Municipio del Salvador/BA. Abogado.

RESUMEN: En el presente artículo se expone los conceptos del problema estructural, proceso estructural y decisión estructural como un desarrollo de la teoría de los procesos estructurales (structural injunctions), propone una clasificación de las características esenciales y de las características típicas que no son esenciales, del proceso estructural, y trata de su procedimiento, con la propuesta de aplicación del procedimiento común, previsto en el Código de Proceso Civil de 2015.

PALABRAS CLAVE: problema estructural; proceso estructural; concepto; características; procedimiento.

ABSTRACT: This essay presents the concepts of structural problem, structural process and structural decision, as a development of the structural injunctions doctrine, proposes a classification of the essential characteristics and typical, but non-essential, characteristics of the structural process, and deals with its procedure, with a proposal to apply to these proceedings the common procedure provided for the 2015 Brazilian Code of Civil Procedure.

KEYWORDS: structural problem; structural process; structural injunctions; concept; characteristics; procedure.

SUMARIO: 1. HISTORIA DEL ASUNTO.-2. CONCEPTOS; 2.1. Problema estructural; 2.2. Proceso estructural; 2.3. Decisión estructural.-3. CARACTERÍSTICAS; 3.1. Características típicas, pero no esenciales: la multipolaridad, la colectividad y la complejidad; 3.2. Características esenciales: el problema estructural, la implementación de un estado ideal de cosas, el procedimiento bifásico y flexible, y la consensualidad.-4. PROCEDIMIENTO;4.1. Flexibilidad intrínseca y consensualidad; 4.2. Las dos fases del proceso estructural: el standard del proceso de quiebra; 4.3. Algunas técnicas de flexibilización del procedimiento en el proceso estructural; 4.4. Adopción del procedimiento común de CPC, con tránsito de técnicas.5. CONCLUSIÓN.-6. REFERENCIAS BIBLIOGRÁFICAS. 


\section{HISTORIA DEL ASUNTO}

La noción de proceso estructural surgió en los Estados Unidos, a partir del activismo judicial que marcó el desempeño del Poder Judicial norteamericano entre 1950 y $1970^{1}$. Se trata de una concepción con un carácter muy pragmático. Sobre la definición analítica o la categorización sistemática de este tipo de actuación por parte del Poder Judicial ${ }^{2}$ no existen grandes preocupaciones.

Todo comenzó en 1954, con el caso Brown vs. Board of Education of Topeka. La Corte Suprema de los Estados Unidos entendió que la admisión de estudiantes a escuelas públicas americanas basadas en un sistema de segregación racial era inconstitucional. Al determinar la aceptación de la matrícula de estudiantes afroamericanos en una escuela pública, hasta entonces dedicada a la educación de personas blancas, la Corte Suprema comenzó un amplio proceso de cambio del sistema de educación pública en ese país, dando lugar a lo que se llamó una structural reform ${ }^{3}$.

Eso fue solo el comienzo.

Según Owen Fiss, "el sistema de educación pública fue objeto del caso Brown, pero con el tiempo las reformas estructurales fueron extendiéndose hasta incluir a la policía, las cárceles, los manicomios, las instituciones para personas con discapacidad mental, autoridades públicas de bonificación para vivienda y agencias de bienestar social" ${ }^{4}$. En otras palabras, el modelo de decisión emitida en el caso Brown vs. Board of Education of Topeka, se expandió y fue adoptado en otros casos, de modo que el Poder Judicial de los Estados Unidos, a través de sus decisiones, comenzó a imponer amplias reformas estructurales en ciertas instituciones burocráticas, con el objetivo que determinados valores constitucionales sean atendidos.

Otro buen ejemplo son los casos Holt v. Sarver, a través del cual todo el sistema penitenciario del estado de Arkansas, en los Estados Unidos, fue impugnado judicialmente con demandas que tuvieron por objeto una reforma completa del sistema penitenciario y que sirvieron de base para otras deman-

1 JOBIM, Marco Félix. Medidas estruturantes: da Suprema Corte Estadunidense ao Supremo Tribunal Federal. Porto Alegre: Livraria do Advogado Editora, 2013, p. 93.

2 Según Eduardo José da Fonseca Costa, "La procesalística brasileña está dotada de una envidiable capacidad analítica para elaborar conceptualizaciones, definiciones, distinciones, clasificaciones y sistematizaciones. Sin embargo, jamás se dignó a desarrollar estudios convincentes sobre la hermenéutica jurídica. Además, todavía está arrastrándose en el arte pragmático de librarse sin culpa de argumentos de coherencia analítica que deben guiarse por aquellos que promueven una mayor practicidad de los resultados" (COSTA, Eduardo José da Fonseca. "A “execução negociada” de políticas públicas em juízo”. Revista de Processo. São Paulo: RT, ano 37, v. 212, outubro/2012, p. 46).

3 FISS, Owen. "Two models of adjudication". In: DIDIER JR. Fredie, JORDÃO, Eduardo Ferreira (coords.). Teoria do processo: panorama doutrinário mundial. Salvador: Juspodivm, 2008, p. 761.

4 Traducción libre, en el original: "The public school system was the subject of the Brown suit, but in time structural reform was broadened to include the police, prisons, mental hospitals, institutions for the mentally retarded, public housing authorities, and social welfare agencies. Structural reform reached as far as the modern bureaucratic state" (FISS, Owen. "Two models of adjudication", cit., p. 761). 
das similares, que posteriormente fueron presentadas (en 1993) contra otros cuarenta estados norteamericanos ${ }^{5}$.

A partir de estas situaciones puntuales, la decisión estructural (structural injunction) se definió como aquella que busca implementar una reforma estructural (structural reform) en una entidad, organización o institución, con el objetivo de concretizar un derecho fundamental, realizar una determinada política pública o resolver litigios complejos ${ }^{6}$. Por ello, el proceso donde se construye se ha denominado proceso estructural ${ }^{7}$. Se parte de la premisa de que la amenaza o el daño que las organizaciones burocráticas representan para la efectividad de las normas constitucionales, no pueden eliminarse sin que dichas organizaciones sean reformadas ${ }^{8}$.

\section{CONCEPTOS}

Es natural que, a partir de la historia sobre el asunto, se pretenda vincular la noción de proceso estructural con los casos donde se discuten cuestiones muy complejas, relativas a los derechos fundamentales y en los que se busca interferir en la estructura de las entidades, instituciones o en las políticas públicas.

5 VIOLIN, Jordão. "Holt v. Sarver e a reforma do sistema prisional no Arkansas". Processos estruturais. Sérgio Cruz Arenhart e Marco Félix Jobim (org). 2 ed. Salvador: Juspodivm, 2019, p. 505.

${ }^{6}$ Los litigios complejos, en este contexto, no implican discusiones sobre tesis jurídicas complejas o sobre muchas cuestiones de hecho, sino que ponen múltiples intereses sociales en curso de colisión, todos ellos dignos de tutela. Un buen punto de partida para comprender sobre la litigiosidad compleja se puede encontrar en el pensamiento de Edilson Vitorelli, cuando se ocupa de lo que llama litigios de difusión irradiada: "Se trata de situaciones en que el litigio derivado de la lesión afecta directamente los intereses de varias personas o segmentos sociales, pero estas personas no forman parte de una comunidad, no tienen la misma perspectiva social y no se verán afectadas, en la misma medida, por el resultado del litigio, lo que hace que sus visiones acerca del resultado deseable sean divergentes y, no raramente, antagónicos. Estas situaciones dan lugar a conflictos mutables y multipolares, ya que el grupo que es titular del derecho se opone no solo al demandado, sino también a sí mismo. Un ejemplo de ello, son los conflictos derivados de la instalación de una planta hidroeléctrica. Si, al inicio del proceso de licenciamiento, se discuten los posibles impactos de la instalación de la planta, en su aspecto social y ambiental, la fase de construcción cambia el escenario de la localidad, con la llegada de grandes contingentes de trabajadores que alteran la dinámica social. Los problemas se vuelven otros, a menudos imprevistos, y los grupos afectados ya no son los mismos que eran en el primer momento, en el que se decidieron los límites del proyecto. En el ámbito ambiental, el curso o flujo de las aguas del río se altera, bloqueando los caminos y separando las comunidades antes vecinas. Las personas son desplazadas. En el entorno natural, la fauna y la flora sufren impactos significativos. Con el final de las obras, toda la dinámica cambia nuevamente. Muchos trabajadores que vinieron, se van. Otros se quedan. Las personas desplazadas forman nuevos barrios y poblaciones, que requieren la implementación de nuevos servicios públicos. Solo debido a la realización de una obra, el medio ambiente natural y la dinámica social se altera de tal manera que la sociedad que existía en ese lugar adquiere características totalmente diferentes de las que existía originalmente" (LIMA, Edilson Vitorelli Diniz. "Tipologia dos litígios transindividuais: um novo ponto de partida para a tutela coletiva”. Repercussões do novo CPC processo coletivo. Hermes Zaneti Jr. (coord.). Salvador: Editora Jus Podivm, 2015, p. 97-98).

7 LIMA, Edilson Vitorelli Diniz. O devido processo legal coletivo: representação, participação e efetividade da tutela jurisdicional. Tese de doutorado apresentada à Faculdade de Direito da Universidade Federal do Paraná (UFPR). Curitiba, 2015, p. 563.

8 FISS, Owen. Two models of adjudication, cit., p. 761. 
No obstante, la verdad es que - aunque este sea el contexto donde es posible recoger la mayor cantidad de ejemplos sobre procesos estructurales-, la noción de proceso estructural puede separarse de estas características.

El concepto de un proceso estructural presupone el de un problema estructural. Este último es un concepto clave. Veamos.

\subsection{Problema estructural}

El problema estructural se define por la existencia de un estado de disconformidad estructurada: una situación de ilegalidad continua y permanente o una situación de disconformidad, aunque no propiamente ilícita, en el sentido de que es una situación que no corresponde al estado de cosas considerado ideal. En cualquier caso, el problema estructural se configura a partir de un estado de cosas que necesita una reorganización (o reestructuración).

Un estado de disconformidad, como se dijo, no es necesariamente sinónimo de un estado de ilicitud o un estado de cosas ilícitas, sino es una situación de desorganización estructural, una ruptura con la normalidad o con el estado ideal de las cosas, que exige una intervención (re)estructurante. Esta desorganización puede, o no, ser el resultado de un conjunto de actos o conductas ilegales.

Puede ser que el problema estructural genere situaciones ilícitas y cada situación aislada merezca un tratamiento por parte del ordenamiento jurídico; incluso puede ser que se observen grados de ilicitud más o menos graves en relación con el problema estructural (ilicitud estructural).

Lo que queremos enfatizar es que el problema estructural no se basa necesariamente en la noción de ilicitud y, cuando eventualmente lo hace, no debe confundirse, en sí mismo, con las situaciones ilícitas que surgen de él. Su tratamiento no se basa en la noción de ilicitud, aunque esta puede ocurrir y casi siempre lo hace.

Existe un problema estructural cuando, por ejemplo: (i) el derecho de tránsito de personas con necesidades especiales se ve afectado por la falta de adecuación y accesibilidad de vías, lugares públicos, edificios e instalaciones públicas en un lugar determinado; (ii) el derecho a la salud de una comunidad se ve afectado por la falta de un plan para combatir el mosquito aedes aegypti por parte de las autoridades de un municipio determinado; (iii) los derechos de los afrodescendientes y de los pueblos indígenas se ven afectados por la falta de previsión, en una determinada estructura curricular de educación pública, de disciplinas o temas relacionados con la historia de esta comunidad; (iv) la dignidad, la vida y la integridad física de la población carcelaria se ven afectadas por la falta de medidas de adecuación de los edificios públicos donde esas personas se encuentran encarceladas.

Pero los problemas estructurales no se restringen a aquellos que tienen experiencia en la esfera pública, o que están vinculados a derechos fundamen- 
tales o políticas públicas, como puede sugerir la enumeración de los ejemplos anteriores.

Las acciones concursales — como, por ejemplo, la quiebra y la recuperación judicial- también se basan en problemas estructurales. Ellas parten de una situación de desorganización, donde hay una ruptura de la normalidad y del estado ideal de cosas, y requieren una intervención (re)estructurante, que organice las cuentas de la empresa en recuperación o que organice los pagos adeudados por el patrimonio en quiebra. Esta desorganización puede provenir de un acto ilícito, como en el caso de la quiebra, o no necesariamente, como en el caso de la recuperación judicial ${ }^{9}$.

La disolución de una empresa o el cierre de una fábrica pueden configurar un problema estructural.

Imagínese que se trate de una empresa con una marcada importancia para la economía local, que emplea a varios trabajadores y genera ingresos para innumerables familias. Basta recordar las situaciones en que las unidades de ensambladoras de vehículos automotores están cerradas y las autoridades están preocupadas por la desmovilización del personal operativo. El cierre de una fábrica no es necesariamente un acto ilegal, pero es una situación que puede romper con el estado de cosas considerado ideal, con amplias repercusiones en la vida de una determinada comunidad, que requiere una intervención de reestructuración.

Otro ejemplo en el ámbito privado es brindado por Sérgio Cruz Arenhart, al tratar la Ley n. 12.529/2011, que estructura el sistema de defensa de la competencia, permitiendo al Consejo Administrativo de Defensa Económica (CADE), entre otras cosas, efectivizar sus decisiones mediante la intervención en la empresa (art. 96), inclusive formulando un pedido de autorización judicial para la intervención y administración total de la empresa (art. 107, § 2) ${ }^{10}$.

Como dice acertadamente Matheus Souza Galdino, "es posible hablar de grados de estructuralidad de acuerdo con el alcance de los efectos de la reestructuración promovida" ${ }^{11}$. El autor nos ofrece una excelente metáfora para demostrar estos grados de estructuralidad del problema: "Un árbol cuyos frutos son venenosos puede recibir una tutela inhibitoria por un proceso con bajo o ningún grado de estructuralidad, lo que permitiría cosechar los frutos y enviarlos a una eliminación segura Ciertamente, otros frutos aparecerían en el otoño siguiente

9 Felipe Vieira Batista también ve a la recuperación judicial como un proceso estructural: "Aunque la Ley $\mathrm{N}^{\circ} 11.101 / 2005$ exige que la petición inicial indique las causas de la crisis, el objetivo no es imputar el referido hecho a un determinado sujeto procesal y/o imponerle cualquier tipo de reparación o sanción por lo sucedido — no existiendo el litigio sostenido. La perspectiva es otra, de una naturaleza mucho más prospectiva: se solicita la intervención/reforma estatal en el sentido de viabilizar/facilitar la resolución de un problema social grave por medio de una negociación de un plan de reestructuración de la actividad (y no con la imposición de una forma de reparación y/o sanción)" (BATISTA, Felipe Vieira. A recuperação judicial como processo coletivo. Dissertação de Mestrado. Salvador: Universidade Federal da Bahia (UFBA), 2017, p. 118).

10 ARENHART, Sérgio Cruz. Decisões estruturais no direito processual civil brasileiro, cit., pp. 403404.

11 GALDINO, Matheus Souza. Elementos para uma compreensão tipológica dos processos estruturais. Dissertação de Mestrado. Salvador: Universidade Federal da Bahia (UFBA), 2019, p. 138. 
y el mismo procedimiento podría adoptarse todas las veces, mediante otro proceso. Un grado más alto de estructuralidad estaría dirigido no solo a cosechar el fruto, sino también a cortar las ramas del árbol. En ese caso, posiblemente, por un tiempo no nacerían nuevos frutos, al menos hasta que broten nuevas ramas y surjan frutos. El siguiente razonamiento ya es predecible. Un proceso que tenga por objeto cortar el tronco del árbol tendría un grado de estructuralidad mucho mayor y, posiblemente, más bajo si se compara con el proceso de cortar el árbol desde la raíz, que en nuestra metáfora tendría un grado máximo de estructuralidad" 12 .

El concepto de grados de estructuralidad está vinculado, por tanto, a la misma lógica que permite hablar de grados de ilicitud. Cabe resaltar que el problema estructural no debe confundirse con la situación de ilicitud, pues dicho problema puede ser y casi siempre es más amplio y su tratamiento depende de una visión más amplia de aquella vinculada a lo ilícito.

Es importante considerar que, con la existencia de un estado de disconformidad, el problema no se puede resolver con un solo acto, como una decisión que certifica un derecho e impone una obligación. Es necesario intervenir para promover una reorganización o reestructuración de la situación ${ }^{13}$, como en los casos donde es necesario cambiar la estructura de la entidad pública, la organización burocrática, etc. Esta intervención normalmente es duradera y requiere un seguimiento continuo.

\subsection{Proceso estructural}

El proceso estructural es aquel donde se desarrolla un litigio estructural, basado en un problema estructural, y donde se pretende cambiar ese estado de disconformidad, reemplazándolo por un estado de cosas ideal ${ }^{14}$.

El mejor camino para llegar a la definición de un proceso estructural es adoptar un razonamiento tipológico ${ }^{15}$ : el proceso estructural presenta ciertas

12 GALDINO, Matheus Souza. Elementos para uma compreensão tipológica dos processos estruturais. Dissertação de Mestrado. Salvador: Universidade Federal da Bahia (UFBA), 2019, p. 139.

13 GALDINO, Matheus Souza. "Breves reflexões sobre as consequências de uma compreensão teleológica dos fatos para a teoria do processo estrutural”. Processos estruturais. Sérgio Cruz Arenhart e Marco Félix Jobim (orgs.). 2 ed. Salvador: Juspodivm, 2019, p. 705.

14 Para Edilson Vitorelli, "el proceso estructural es un proceso colectivo donde se pretende, a través de la actuación jurisdiccional, la reorganización de una estructura burocrática, pública o privada, que causa, fomenta o viabiliza la ocurrencia de una violación por la forma en cómo funciona, originando un litigio estructural" (VITORELLI, Edilson. "Levando os conceitos a sério: processo estrutural, processo coletivo, processo estratégico e suas diferenças”. Revista de Processo. São Paulo: Thomson Reuters, outubro/2018, v. 284, p. 333-369). Como se observa, Vitorelli presenta un concepto más limitado sobre proceso estructural, enfatizando que se trata de un proceso colectivo (una característica que, para nosotros, es típica, pero no esencial), dirigido a la reestructuración de una institución pública o privada (mientras nosotros destacamos el propósito de reestructurar un estado de disconformidad, sin vincularlo necesariamente a una institución pública o privada), en razón de que esta ha incurrido en alguna violación a la norma (mientras que para nosotros el estado de disconformidad no es, necesariamente, un estado de ilicitud).

15 Con amplias consideraciones: GALDINO, Matheus Souza. Elementos para uma compreensão tipológica dos processos estruturais. Dissertação de Mestrado. Salvador: Universidade Federal da Bahia 
características típicas, pero para definirse como un proceso estructural, no es necesario que todas estas características estén presentes.

Para ejemplificar el razonamiento tipológico, piénsese en la labor del médico al diagnosticar una determinada enfermedad: examina las características (síntomas) presentadas por el paciente, compara estas características con aquellas que son típicas en ciertas dolencias y llega a una conclusión; muchas dolencias se revelan a través de características (síntomas) típicas, pero no es necesario que todas ellas estén presentes para llegar al diagnóstico de aquella enfermedad; no siempre, por ejemplo, el paciente siente dolores de cabeza y, aun así, su diagnóstico puede ser de gripe, porque el dolor de cabeza es una característica (síntoma) típica, pero no esencial de la gripe.

El proceso estructural se caracteriza por: (i) basarse en la discusión de un problema estructural, un estado de cosas ilícito, un estado de disconformidad, o cualquier otro nombre que se quiera utilizar para designar una situación de disconformidad estructurada; (ii) buscar una transición de ese estado de disconformidad a un estado ideal de $\operatorname{cosas}^{16}$ (en consecuencia, una reestructuración), eliminando la situación de disconformidad, mediante una decisión de implementación escalonada; (iii) desarrollarse en un procedimiento bifásico, que incluye el reconocimiento y la definición del problema estructural y establece el programa o proyecto de reestructuración que se seguirá; (iv) desarrollar en un procedimiento marcado por su flexibilidad intrínseca, con la posibilidad de adoptar formas atípicas de intervención de terceros y medidas ejecutivas, de alterar el objeto litigioso, de utilizar mecanismos de cooperación judicial; y (v) la consensualidad, que abarque incluso la adaptación del proceso (art. 190, CPC).

El proceso estructural también presenta algunas características típicas, pero no esenciales: la multipolaridad, la colectividad y la complejidad. Estas características se analizarán más adelante.

El objetivo inmediato del proceso estructural es alcanzar el estado ideal de $\operatorname{cosas}^{17}$, por ejemplo, un sistema educativo libre de segregación; un sistema penitenciario en el que se garantice la dignidad del preso y la posibilidad de su resocialización; un sistema de salud universal e igualitario y también la preser-

(UFBA), 2019, p. 125 y siguientes.

16 Matheus Galdino, en un excelente trabajo, señala que el proceso estructural se caracteriza por dar más relevancia a la comprensión teleológica de los hechos que a la relación causal. Si bien es importante comprender el estado de cosas actual a partir de un análisis basado en la causalidad, investigando los hechos de la vida que generaron ese estado actual de disconformidad (relación entre causa y efecto), en el proceso estructural es más relevante investigar el estado de cosas ideal, aquel que se quiere implementar en el futuro, proyectando el camino que debe seguirse para alcanzarlo (relación entre medios y fines) (GALDINO, Matheus Souza. "Breves reflexões sobre as consequências de uma compreensão teleológica dos fatos para a teoria do processo estrutural”. Processos estruturais. Sérgio Cruz Arenhart e Marco Félix Jobim (orgs.). 2 ed. Salvador: Juspodivm, 2019, p. 685-694).

17 En ese mismo sentido: GALDINO, Matheus Souza. "Breves reflexões sobre as consequências de uma compreensão teleológica dos fatos para a teoria do processo estrutural”. Processos estruturais. Sérgio Cruz Arenhart e Marco Félix Jobim (orgs.). 2 ed. Salvador: Juspodivm, 2019, p. 698-704. 
vación de la empresa recuperada. En tales casos, buscamos eliminar el estado de disconformidad, promoviendo una transición al estado de conformidad.

En razón a la lista de ejemplos de problemas estructurales establecidos en el párrafo anterior, podemos decir que los ejemplos sobre procesos estructurales son aquellos provocados por una: (i) demanda que, busca la concretización de los derechos de tránsito de las personas con necesidades especiales, a través de un plan de adecuación y accesibilidad en las vías, lugares públicos, edificios e instalaciones públicas de una determinada localidad; (ii) demanda que, busca garantizar el derecho a la salud y que, considerando el crecimiento del número de casos de microcefalia en una región determinada y su posible relación con el virus zika, se impone un plan para combatir el mosquito aedes aegypti, prescribiendo una serie de conductas para las autoridades municipales; (iii) demanda que, buscando salvaguardar los derechos de las minorías, solicita la inclusión, en la estructura curricular de la escuela pública, de disciplinas o temas relacionados a la historia de los africanos y de los pueblos indígenas; (iv) demanda que, pretender garantizar la dignidad, la vida y la integridad física de la población carcelaria y, para ese propósito, exige la adopción de medidas de adecuación de los edificios públicos donde estas personas se encuentran encarceladas.

\subsection{Decisión estructural}

En ese sentido, la decisión estructural es aquella que, partiendo de la verificación de un estado de disconformidad, establece el estado ideal de las cosas que se pretende implementar (fin) y el modo por el cual ese resultado debe ser alcanzado (medios). En esencia, la decisión estructural no estructura, pero sí reestructura lo que estaba desorganizado.

Esa decisión tiene un contenido complejo.

Primero, porque ella prescribe una norma jurídica de contenido abierto; su precepto indica un resultado a ser alcanzado - una meta, un objetivoasumiendo, por tanto, y en esa parte, la estructura deóntica de una normaprincipio.

En segundo lugar, porque estructura el modo en cómo se debe alcanzar ese resultado, determinando los comportamientos que deben observarse o evitarse para que el precepto sea cumplido y el resultado sea alcanzado, por lo tanto, y en esa parte, la estructura deóntica es el de una norma-regla.

El Supremo Tribunal Federal ya ha emitido algunas decisiones que pueden considerarse estructurales ${ }^{18}$.

18 Con respecto a los métodos de conducción dialógica que puede adoptar el Supremo Tribunal Federal y recordando que, en algunos de los casos que se citarán aquí, el STF no usó estos métodos, SARAIVA, Carolina Barros. "Condução dialógica dos processos estruturais no Supremo Tribunal Federal”. Processos estruturais. Sérgio Cruz Arenhart e Marco Félix Jobim (org). 2 ed. Salvador: Juspodivm, 2019, p. 209 y siguientes. 
En el caso Raposa Serra del Sol (Acción Popular n. 3.388/RR), por ejemplo, el STF admitió la demarcación de la tierra a favor de un grupo de indígenas, pero estableció diversas "condiciones" para el ejercicio, por parte de los indios, del usufructo de la tierra demarcada, entre ellos, la necesidad de que el usufructo esté condicionado al interés de la Política de Defensa Nacional, ya que las tierras indígenas están situadas en la zona fronteriza del país ${ }^{19}$. Además, se dieron vida a diversos hitos que deberían considerarse en el proceso administrativo para la identificación y demarcación de las tierras indígenas.

Este caso es emblemático, porque revela una característica de las decisiones estructurales, inclusive la imposición de un régimen jurídico de transición entre la situación anterior y aquella que se busca implementar, concretizándose, de ese modo, el principio de seguridad jurídica.

Otro ejemplo es la decisión emitida en el Mandato de Inyunción n. 708/DF, donde el STF se ocupó del ejercicio del derecho de huelga de los servidores públicos civiles. En esa oportunidad, se constató que la omisión legislativa con respecto a la regulación del tema persistía, a pesar de las anteriores decisiones en las que se reconoció que había una demora de los órganos legislativos. Se entendió que, para no caracterizar una omisión judicial, era necesario superar esta situación de omisión y, frente a ello, se determinó, entre otras cosas, que sea aplicado al caso la Ley n. 7.783/1989, que regula el derecho de huelga de los trabajadores celetistas" en general, con las adaptaciones necesarias, "siempre que la omisión no esté regulada adecuadamente por una ley específica para los servidores públicos civiles (CF, art. 37, VII)” ${ }^{20}$.

La decisión emitida por el STF en la ADPF n. 378, con respecto al trámite del proceso de impeachment (Ley 1.079/1950), puede considerarse como otro ejemplo más de una decisión estructural. Según el fallo, "por mayoría, los ministros entendieron que corresponde a la Cámara de Diputados autorizar únicamente al Senado a iniciar el proceso, siendo el Senado responsable de emitir el juicio inicial de instalación o no del procedimiento, cuando la votación se diera por mayoría simple. También se fijó que la votación para elegir a la comisión especial de la Cámara deba ser abierta, siendo ilegítimas las candidaturas individuales de diputados para su composición, y que la destitución del cargo de presidente se produce después de que el Senado procese la denuncia" 21 .

En todos estos casos, aunque no hubiese necesariamente un estado previo de ilicitud, sí existe un estado anterior de disconformidad —la ausencia

19 STF, Pet 3388, Tribunal Pleno, rel. Min. Carlos Ayres Britto, j. 19.03.2009, DJe 24.09.2009.

* [N. del T.]: El término "celetista" proviene de la sigla CLT que, en Brasil, significa "Consolidación de las Leyes de Trabajo". Un "celetista" es, por tanto, un trabajador que pertenece a un régimen laboral regulado por la CLT.

20 STF, MI 708, Tribunal Pleno, rel. Min. Gilmar Mendes, j. 25/10/2007, DJe 30.10.2008.

21 Disponible en: http://www.stf.jus.br/portal/cms/verNoticiaDetalhe.asp?idConteudo=306611 Acceso el 23/dic/ 2015. 
de definición requiere de los límites que deberían analizarse en el proceso administrativo para la identificación y demarcación de las tierras indígenas, ausencia de regulaciones específicas sobre el derecho de huelga a los servidores civiles, ausencia de una definición precisa de las etapas y atribuciones del proceso de impeachment-; que se buscó sustituir por un estado ideal de cosas, donde esas indefiniciones fuesen superadas.

\section{CARACTERÍSTICAS}

\subsection{Características típicas, pero no esenciales: la multipolaridad, la colectividad y la complejidad}

Como se vio anteriormente, el proceso estructural tiene ciertas características típicas, pero no esenciales. Esto significa que tales características sugieren que se trata de un proceso estructural, sin embargo, no necesariamente tienen que estar presentes para que el proceso sea considerado estructural, pues el proceso estructural puede existir sin ellas.

(i) La multipolaridad es una característica típica del proceso estructural. Para Sérgio Cruz Arenhart, "el conflicto estructural funciona con la lógica de la formación de varios núcleos de posiciones y opiniones (muchas de ellas antagónicas) con respecto al tema a tratar" 22.

En estos casos, la lógica binaria del proceso individual — que se opone a los intereses de los dos polos (demandante y demandado), bajo la premisa de que estos intereses son siempre antagónicos y que los intereses de los litisconsortes que eventualmente ocupan cada uno de estos polos son siempre convergentes- difícilmente se aplica a los procesos estructurales. En ellos, debido a la naturaleza estructural del problema, es común que haya una multiplicidad de intereses involucrados, que se polarizan dependiendo de la cuestión discutida: el mismo grupo de personas puede alinearse con los intereses de otro grupo en un tema determinado, pero no en otros.

Imagínese una acción civil pública donde el Ministerio Público pretenda imponer a una determinada concesionaria de carretera federal, el deber de realizar múltiples obras en la red de carreteras y en sus alrededores, exactamente como se estipula en el contrato de concesión suscrito una década antes. Imagine que, si se implementa en los términos exactos previstos en el contrato, esas obras terminarían segregando un vecindario completo, que floreció en los últimos diez años alrededor de cierto tramo de la carretera; la implementación de guard rails en la carretera, que reduce el vecindario a la mitad, asociada a la inexistencia, en el proyecto inicial del contrato de vías de acceso para vehículos, puente para peatonales y retornos, todo eso terminaría por impedir $-\mathrm{o}$, al menos, por hacerlo muy difícil- el tránsito de los residentes locales de un lado al otro, segregando a las familias y vecinos.

22 ARENHART, Sérgio Cruz. "Processo multipolar, participação e representação de interesses concorrentes”. Processos estruturais. Sérgio Cruz Arenhart e Marco Félix Jobim (orgs.). 2 ed. Salvador: Juspodivm, 2019, p. 800. 


\begin{abstract}
Aunque el Ministerio Público por ley, tenga la legitimidad para dar voz a la voluntad colectiva, es muy posible que, entre el Ministerio Público que formuló la demanda y la comunidad del vecindario en cuestión, haya un desacuerdo de intereses; y entre ellos y la concesionaria, muchas otras diferencias; e incluso entre ellos, la concesionaria y la agencia reguladora (en el caso, ANTT), otros desacuerdos más. Son innumerables las cuestiones potencialmente involucradas con innumerables posibilidades de adecuación a los diferentes intereses.
\end{abstract}

Sin embargo, como se indicó anteriormente, la multipolaridad no es una característica esencial del proceso estructural, ni es una característica determinante. Es posible que el proceso sea estructural y bipolar, es decir, involucra solo dos polos de intereses. También es posible que, a pesar de la multipolaridad, el proceso no sea estructural ${ }^{23}$.

(ii) Como consecuencia de esto, tampoco es una característica esencial del proceso estructural que sea colectivo. "Colectivo es el proceso que tiene por objeto litigioso una situación jurídica colectiva activa o pasiva" 24 .

Aunque normalmente el proceso estructural sea colectivo, ya que discute una situación jurídica colectiva, es posible que un proceso promovido por una demanda individual se base en un problema estructural y, por lo tanto, deba tratarse como un proceso estructural ${ }^{25}$. Esto sucede especialmente cuando se produce el fenómeno de la múltiple incidencia, que se caracteriza cuando el mismo hecho puede "afectar la esfera de situaciones jurídicas individuales y situaciones jurídicas colectivas" ${ }^{26}$.

23 Sofia Temer también reconoce la multipolaridad como una característica del proceso estructural, pero recuerda que "la multipolaridad no se limita a litigios calificados como 'complejos' o 'no tradicionales' [...]. Por el contrario, la estructura multipolarizada puede ocurrir en cualquier proceso, incluso en aquellos que se ocupan de conflictos 'tradicionales', es decir, los llamados procesos 'por excelencia”" (TEMER, Sofia Orberg. "Participação no processo judicial: arranjos subjetivos e modalidades de atuação". Tese de doutorado. Rio de Janeiro: Universidade do Estado do Rio de Janeiro (UERJ), 2020, p. 168).

${ }^{24}$ DIDIER JR., Fredie; ZANETI JR., Hermes. “Conceito de processo jurisdicional coletivo”. Revista de Processo. São Paulo: RT, 2014, v. 229, p. 273.

${ }_{25}$ En sentido contrario, entendiendo que el proceso estructural es necesariamente colectivo, VITORELLI, Edilson. "Levando os conceitos a sério: processo estrutural, processo coletivo, processo estratégico e suas diferenças”. Revista de Processo. São Paulo: Thomson Reuters, outubro/2018, v. 284, p. 333-369. En el mismo sentido, admitiendo que "muchas demandas estructurantes son formalmente individuales (bipolares), no obstante, en razón a su objeto no pueden ser adecuadamente resueltos mediante los mecanismos y procedimientos tradicionales de resolución de conflictos": TOSTA, André Ribeiro; MARÇAL, Felipe Barreto. "Gerenciamento processual adequado de demandas formalmente individuais a partir de uma visão estruturante: o reforço proporcionado pelo art. 21 da LINDB”. Processos estruturais. Sérgio Cruz Arenhart e Marco Félix Jobim (org). 2 ed. Salvador: Juspodivm, 2019, p. 189. Marcela Ferraro también comprende que, en algunos casos, "el derecho es individual, pero su violación se muestra estructural y la carga policéntrica es tanta que no se debe tratar la cuestión individualmente, pues el proceso individual resulta inadecuado" (FERRARO, Marcella Pereira. Do processo bipolar a um processo coletivo-estrutural. Dissertação de Mestrado. Curitiba: Universidade Federal do Paraná (UFPR), 2015, p. 145).

26 DIDIER JR., Fredie; ZANETI JR., Hermes. “Comentários ao art. 333 do CPC-2015”. Breves comentários ao novo Código de Processo Civil. Teresa Arruda Alvim Wambier, Fredie Didier Jr., Eduardo Talamini e Bruno Dantas (coords). 3 ed. São Paulo: RT, 2016, p. 958. 
Imagine que un sujeto, con discapacidad o con movilidad reducida, ingresa con una acción individual, en razón a los derechos que le garantiza la Ley n. 10,098/2000 27, para exigir que determinados edificios públicos o privados, de uso colectivo, a los que necesita tener acceso de manera recurrente (como su universidad, el hospital de su vecindario, el banco donde tiene una cuenta corriente, etc.), sean obligados a promover reformas que garanticen la accesibilidad prevista en la ley.

Esta es típicamente una acción individual, pero tiene una inequívoca naturaleza estructurante. Su causa de pedir consiste en la afirmación de una situación de disconformidad, debido a un incumplimiento permanente de la legislación que impone la promoción de la accesibilidad de estos lugares. Hay un ambiente de ilicitud que necesita de una intervención (re)estructurante porque de ese nuevo e ideal estado de cosas depende de la satisfacción del derecho del demandante-individuo.

Existe, en ese sentido, un problema estructural por el cual se requiere una decisión que proyecte e implemente un nuevo e ideal estado de $\operatorname{cosas}^{28}$.

Otros casos donde la demanda es, en principio, individual también pueden tener una naturaleza estructurante, como la pretensión de la mujer profesional por un tratamiento igualitario dentro de determinada empresa, o como la pretensión de un detenido no católico por asistencia religiosa específica o por el respeto a sus costumbres (alimentos, por ejemplo) dentro de la prisión.

Obsérvese que, en este ejemplo, se tiene una acción individual cuyo resultado puede tener un alcance colectivo. La promoción de la accesibilidad requerida por el demandante-individual naturalmente no solo le servirá a él, sino también a todos aquellos que utilicen los mismos espacios en los que se afirmó que hubo una intervención estructurante.

Fue exactamente este tipo de acción, llamada pseudoindividual, ${ }^{29}$, que fue recogido en el art. 333, I, del CPC, que se ocupó de la posibilidad de conversión, por

27 Ley que establece normas generales y criterios básicos para promover la accesibilidad de las personas con discapacidad o con movilidad reducida, y otras medidas.

28 Para André Ribeiro Tosta y Felipe Barreto Marçal, "tratar una demanda individual como estructurante (o crear un proceso estructurante a partir de demandas individuales) cuando se trata de una violación sistémica de determinados derechos trae más esperanzas y más ventajas que un litigio puntual o a 'cuentagotas', especialmente con fines de macrojusticia y de análisis de los impactos globales de las medidas aplicadas" (TOSTA, André Ribeiro; MARÇAL, Felipe Barreto. "Gerenciamento processual adequado de demandas formalmente individuais a partir de uma visão estruturante: o reforço proporcionado pelo art. 21 da LINDB”. Processos estruturais. Sérgio Cruz Arenhart e Marco Félix Jobim (org). 2 ed. Salvador: Juspodivm, 2019, p. 194).

29 WATANABE, Kazuo. "Relação entre demanda coletiva e demandas individuais". Revista de Processo. São Paulo: RT, 2006, v. 139, p. 29-35. La verdadera acción pseudoindividual, sin embargo, es aquella propuesta como si fuese individual, pero en realidad es una acción colectiva, ya que se introduce una pretensión colectiva en lugar de una pretensión individual. El autor afirma una situación jurídica que es colectiva, aunque se considere que es individual. Es el caso de un individuo que solicita la declaración de inconstitucionalidad de la ley o requiere la invalidación íntegra del edicto del concurso público; si se solicita que la ley o el edicto no afecten su esfera jurídica, apenas la acción sería individual. No es el caso de la acción popular (para lo cual el individuo está legitimado), pues se está delante de una flagrante ilegitimidad activa. 
el juez de primer grado, de la acción individual en acción colectiva, pero cuya redacción recibió el veto presidencial.

(iii) La complejidad es otra característica típica del proceso estructural. Complejo es el proceso donde se discute un problema que admite diversas soluciones ${ }^{30}$. El número de soluciones posibles se da en la medida de la complejidad del proceso.

Es común que el problema estructural se pueda resolver de varias maneras: una vez que se establece la meta a ser alcanzada (el nuevo o ideal estado de cosas), diversos son los medios con los que normalmente se puede implementar. Exactamente por esta razón, Edilson Vitorelli sugiere que los litigios estructurales se clasifiquen en la categoría de litigios irradiados ${ }^{31}$, entendiendo así aquellos que "involucran a un gran grupo de personas, afectadas de diferentes maneras por la controversia, con visiones diferentes sobre cómo debería terminar y, por eso mismo, con intereses diversos, que son representados en el proceso" 32 .

Cabe resaltar que la noción de complejidad está fuertemente relacionada con la noción de multipolaridad: la diversidad de intereses involucrados tiende a multiplicar las posibilidades de tutela. Se observa, claramente que en este tipo de situaciones existe una elevada conflictuosidad interna entre los grupos afectados e incluso dentro del grupo mismo.

Aunque predominen los ejemplos de procesos estructurales de indiscutible complejidad y conflictuosidad, estos atributos no son esenciales para su identificación. El hecho de que, eventualmente, el problema subyacente no admita un número tan diverso de soluciones no descarta la posibilidad de tratarse de un problema estructural -y, por lo tanto, que el proceso en el que se discuta sea, también, un proceso estructural. La cuestión puede ser clara desde un punto de vista jurídico y compleja desde un punto de vista fáctico. Puede ser clara desde un punto de vista jurídico y fáctico, así como difícil de implementar porque implica un cambio cultural.

Ya hemos dicho que es posible identificar diferentes grados de estructuralidad del problema. Hay ciertos estados de disconformidad que exigen una intervención menos intensa del Poder Judicial — como la necesidad de que determinada entidad pública revise la aplicación de los criterios de regulación de las camas dentro del alcance del Sistema Único de Salud (SUS), o que verifique el valor de tope para el pago de los procedimientos de salud clasificados como de mediana y alta complejidad (llamados Tope MAC) realizados

30 VITORELLI, Edilson. O devido processo legal coletivo: dos direitos aos litígios coletivos. 2. ${ }^{\text {a }}$ ed. São Paulo: Thomson Reuters Brasil, 2019, p. 23 e p. 67.

31 VITORELLI, Edilson. "Litígios estruturais: decisão e implementação de mudanças socialmente relevantes pela via processual”. Processos estruturais. Sérgio Cruz Arenhart e Marco Félix Jobim (orgs.). $2^{a}$ ed. Salvador: Juspodivm, 2019, p. 274.

32 VITORELLI, Edilson. $O$ devido processo legal coletivo: dos direitos aos litígios coletivos. $2^{\text {a }}$ ed. São Paulo: Thomson Reuters Brasil, 2019, p. 536. 
por instituciones filantrópicas, sin la necesidad de grandes incursiones en el ámbito del sistema de salud.

No es la mayor o menor complejidad lo que define el proceso como estructural, aunque este indicador contribuye significativamente a su identificación.

\subsection{Características esenciales: el problema estructural, la implementación de un estado ideal de cosas, el procedimiento bifásico y flexible, y la consensualidad}

Esto es lo que nos parece esencial para la caracterización del proceso estructural: (i) el hecho de que en él se discuta un problema estructural; (ii) el hecho de que se busque la implementación de un estado ideal de cosas, reemplazando el estado de disconformidad que caracteriza el problema estructural; (iii) el hecho de que se necesite del desarrollo de un procedimiento bifásico; (iv) la intrínseca flexibilidad del procedimiento; y (v) la consensualidad, incluso en relación con la adaptación del proceso.

Las características "i" y "ii” ya fueron tratados. Ahora, veamos, en el siguiente ítem, las características "iii", "iv" y "v".

\section{PROCEDIMIENTO}

\subsection{Flexibilidad intrínseca y la consensualidad}

Es absolutamente inviable establecer previamente los recorridos procedimentales adecuados para el desarrollo del proceso estructural, considerando la extrema variación de los tipos de litigios estructurales. Como señala Jordão Violin, "modificando el objeto de la acción, varían también las adaptaciones procedimentales necesarias para la protección de la vida. La tutela del derecho a la salud, la vivienda o la erradicación del trabajo infantil, por ejemplo, exigirán medidas diversas de aquellas adoptadas para la desegregación de las escuelas" 33 .

Debido a eso, podemos afirmar que existe - y debe existir-, cierta flexibilidad intrínseca en el procedimiento por el cual se desarrolla el proceso estructural.

Esta flexibilidad del proceso estructural debe estar garantizada (i) por la utilización de un procedimiento bifásico, aprovechando el standard del proceso de quiebra, que puede servir como base debido a la disposición legal expresa de la posibilidad de fraccionar la resolución de mérito (arts. 354, párrafo único, y 356, CPC); y (ii) por la aplicación de técnicas procesales

33 VIOLIN, Jordão. "Holt v. Sarver e a reforma do sistema prisional no Arkansas". Processos estruturais. Sérgio Cruz Arenhart e Marco Félix Jobim (orgs.). 2 ed. Salvador: Juspodivm, 2019, p. 502-503. 
flexibles, como la que atenúa las reglas de congruencia objetiva y de estabilización objetiva de la demanda, la ampliación del régimen de participación en el proceso, la atipicidad de los medios de prueba (art. 369, CPC), la atipicidad de las medidas ejecutivas (art. 139, IV, y art. 536, § 1, CPC), la atipicidad de los instrumentos de cooperación judicial (art. 69, CPC).

Además, la consensualidad tiene una especial importancia en este tipo de proceso.

La posibilidad de ajustar acuerdos procesales (art. 190, CPC) se ve reforzada en los procesos estructurales debido a la usual complejidad y multipolaridad, que están involucradas en su tramitación. Si la solución negociada es siempre preferible en un proceso individual de naturaleza bipolar, donde normalmente resulta fácil identificar a los intereses opuestos, tanto más si se puede decir cuando hay múltiples intereses involucrados - convergentes o divergentes, dependiendo de la cuestión analizada-, y múltiples posibilidades de solución del problema. En el proceso estructural, el requerimiento a la consensualidad se exige aún más.

De ahí la importancia, para el proceso estructural, de las técnicas de negociación, tanto para el objeto del proceso en sí mismo, para la adaptación del procedimiento para ajustarlo a las especificidades de la causa o así como para las cargas, poderes, facultades y deberes de los sujetos procesales.

\subsection{Las dos fases del proceso estructural: el standard del proceso de quiebra}

No existe un procedimiento especial para las acciones destinadas a reestructurar situaciones de disconformidad permanente y generalizada. Pero si existe un standard histórico, que bien puede usarse como base para la organización del proceso estructural: el proceso de quiebra.

Como se ve, en una quiebra se discute un problema estructural, una situación de disconformidad que exige una intervención (re)estructurante; la solución para ese problema fue estructurada en un proceso que se desarrolla en dos fases bien definidas: a) la primera fase, que define la existencia del problema estructural (certificación del estado de quiebra); y b) la segunda fase, la adopción de medidas para estructurar los pagos de la deuda del patrimonio en quiebra.

Ese diseño bien puede adoptarse en otros tipos de procesos estructurales. Veamos. 


\subsubsection{Primera fase: constatación del estado de disconformidad y decisión estructural que establece una meta a ser alcanzada (un nuevo estado de cosas)}

La primera fase del proceso estructural debe dedicarse a constatar la existencia de un problema estructural. Su propósito es, una vez que se identifica el problema, establecer el objetivo a ser alcanzado: el estado ideal de las cosas.

La instrucción probatoria deberá, en este momento, limitarse a investigar la existencia de ese estado permanente/generalizado de disconformidad -la prueba de muestra ${ }^{34}$ y la prueba estadística ${ }^{35}$ son fundamentales para esto.

También es importante hacer adaptaciones al procedimiento para que se pueda trabajar el problema estructural. Entre ellos, es necesario atenuar la regla de congruencia objetiva externa, admitiendo incluso la posibilidad de cambiar el objeto del pedido; es necesario promover una apertura del proceso a la participación de terceros, garantizando una mayor legitimidad democrática; es necesario optimizar la producción probatoria, adaptándola al problema en cuestión, que usualmente presupone la investigación de múltiples cuestiones de hecho, a menudo difusas o indeterminadas.

Abordaremos este tema más adelante.

La primera fase del procedimiento termina con la decisión estructural, en caso se constate el estado de disconformidad sostenido. Esta decisión, como ya se vio, tiene un contenido programático, al establecer una meta a ser alcanzada (el estado ideal de las cosas).

Esta decisión puede establecer, desde ese momento, los medios para la reestructuración deseada, que se buscará en la segunda fase del proceso estructural, si el juez tiene las condiciones para definirlas en ese momento. Pero también es posible que estos medios se definan más adelante, si el juez siente la necesidad, por ejemplo, en la segunda fase, de consultar a expertos sobre los caminos que se pueden tomar para alcanzar la meta establecida.

Lo que define este momento procesal es que, en cualquier caso, la decisión estructural no culmina la función jurisdiccional. Solo comienza lo que probablemente sea la fase más duradera del proceso estructural, marcada por la participación efectiva del juez (y, naturalmente, de las partes y otros sujetos) para la implementación del nuevo estado de cosas.

34 Para apreciar, por ejemplo, si la entidad pública ha estado respetando las reglas de accesibilidad en la construcción y reformas de los edificios públicos; no es necesario verificar esta circunstancia en cada uno de los edificios públicos existentes, siempre que esta demostración se realice mediante el muestreo.

35 Para evaluar, por ejemplo, el número de pacientes que dejaron de ser atendidos en los establecimientos de salud vinculados al SUS y la proporción de este número en relación con la población local total. 


\subsubsection{Segunda fase: implementación de la meta establecida en la decisión estructural}

La segunda fase del proceso estructural comienza con la implementación de las medidas necesarias para alcanzar la meta establecida en la decisión estructural. A diferencia de la primera fase, que sería la certificación del resultado a alcanzar, esta segunda fase sería la ejecución de las medidas necesarias para alcanzar ese resultado proyectado.

Sin embargo, esto no significa que se diga que no exista cognición en esta segunda etapa: tan o más importante que identificar la meta a ser alcanzada (final) es identificar e implementar los mecanismos (medios) adecuados para su alcance.

Como bien identificó Matheus Galdino, las consecuencias de un proceso que produce, como resultado, una decisión que afirma una norma-principio son: “a) la decisión en dicho proceso exigirá una posterior cognición sobre los comportamientos a ser efectivados por sus destinatarios a fin de alcanzar el estado de cosas allí previsto; b) la instrucción en el proceso se centra en la evaluación de la correlación entre el estado de cosas (fin-objeto mediato del proceso) y los efectos de la conducta necesaria a su alcance (medios); y, c) el resultado del proceso, dado su contenido normativo que es principalmente complementario y preliminarmente parcial, le permite que se busque una armonización entre varios estados de cosas" ${ }^{36}$.

4.2.2.1. Definición del tiempo, modo y grado de reestructuración, del régimen de transición y de la forma de evaluación/ fiscalización de las medidas estructurantes.

Para que esta segunda fase se desarrolle con éxito, es necesario que la decisión estructural establezca, al menos: (i) el tiempo, el modo y el grado de reestructuración que se implementará; (ii) el régimen de transición, según el art. 23 de la LINDB; y (iii) la forma de evaluación/fiscalización permanente de las medidas estructurales.

Veamos.

(i) En cuanto al primero, es necesario considerar el caso concreto para evaluar el tiempo adecuado para la reestructuración pretendida.

La decisión estructural, dado el contexto en el que se presenta, no es una que generalmente se implemente de manera rápida, porque la reestructuración de un estado de disconformidad exige, normalmente, tiempo para madurar, no solo para que la reestructuración sea efectiva, sino también para

\footnotetext{
${ }^{36}$ GALDINO, Matheus Souza. "Breves reflexões sobre as consequências de uma compreensão teleológica dos fatos para a teoria do processo estrutural”. Processos estruturais. Sérgio Cruz Arenhart e Marco Félix Jobim (orgs.). 2. a ed. Salvador: Juspodivm, 2019, p. 705.
} 
que sea duradera. Así, se espera que la implementación del estado ideal de cosas demore en ocurrir.

Nada impide que determinadas medidas más urgentes sean implementadas de forma inmediata, aunque de modo atenuante - como la construcción de un acceso temporal para personas con necesidades especiales hasta que las adecuaciones arquitectónicas permanentes sea concluidas, como un alojamiento temporal para determinados detenidos, mientras no se culmine las obras de reforma del establecimiento penitenciario de origen, o como el refugio para familias afectadas por un desastre ambiental, con el pago de un beneficio monetario provisional, hasta que sea posible instalarlas permanentemente en un nuevo espacio.

Con relación al modo como la implementación de la meta establecida debe ser realizada, el juez puede ser, el mismo, el gestor de la reestructuración, o puede rodearse de profesionales debidamente calificados, que pueden ayudarlo adecuadamente. Una medida muy útil, considerando que el juez no siempre tiene el conocimiento y el tiempo necesario para implementar este tipo de decisión.

El art. 99 de la Ley n. 11.101/2005 ${ }^{37}$ (ley de quiebras) establece, por ejemplo, la posibilidad de nombrar un administrador judicial, que puede ayudar

37 "Art. 99. La sentencia que decreta la quiebra del deudor, entre otras determinaciones: I- contendrá la síntesis del pedido, la identificación de la quiebra y los nombres de quienes fueron en ese tiempo sus administradores; II- fijará el plazo legal de la quiebra, sin poder retractarse por más de 90 (noventa) días contados del pedido de quiebra, del pedido de recuperación judicial o del $1^{\circ}$ (primer) protesto por falta de pago, excluyendo, por este propósito, los protestos que han sido cancelados; III- ordenará al quebrado que presente, en el plazo máximo de 5 (cinco) días, la relación nominal de acreedores, indicando la dirección, importancia, naturaleza y clasificación de los créditos respectivos, siempre que no se encuentra en autos, bajo pena de desobediencia; IV- explicitará el plazo para las habilitaciones de crédito, de conformidad con las disposiciones del $\S 1^{\circ}$ del art. 7 de esta Ley; V- ordenará la suspensión de todas las acciones o ejecuciones contra el quebrado, con excepción de los casos previstos en los §§ 1 y 2 del art. 6 de esta Ley; VI- prohibirá la práctica de cualquier acto de disposición o gravamen de los bienes del quebrado, sometiéndolos preliminarmente a una autorización judicial y al Comité, si hubiera, excepto los bienes cuya venta es parte de las actividades normales del deudor si se autoriza la continuación provisional bajo los términos del inciso XI del caput de este artículo; VII- determinará las diligencias necesarias para salvaguardar los intereses de las partes involucradas, pudiendo ordenar la prisión preventiva del quebrado o sus administradores cuando es requerido en razón a las pruebas de la práctica criminal definido en esta Ley; VIII- ordenará al Registro Público de Empresas que proceda con la anotación de la quiebra en el registro de deudores, para que conste la expresión "Quiebra", la fecha del decreto de quiebra y la inhabilitación que se refiere el art. 102 de esta Ley; IX- nombrará al administrador judicial, quien desempeñará sus funciones en la forma establecida en el inciso III del caput del art. 22 de esta Ley, sin perjuicio de lo dispuesto en el literal $a$ del inciso II del caput del art. 35 de esta Ley; $\mathrm{X}$ - determinará la emisión de oficios a los órganos y reparticiones públicas y otras entidades para informar la existencia de bienes y derechos de quebrado; XI- pronunciará respecto de la continuación provisional de las actividades del quebrado con el administrador judicial o el cierre de los establecimientos, observando lo dispuesto en el art. 109 de esta Ley; XII- determinará, cuando se considere conveniente, la convocatoria de la asamblea general de acreedores para la constitución del Comité de Acreedores, teniendo la posibilidad de autorizar el mantenimiento del Comité que eventualmente pueda funcionar en la recuperación judicial cuando se declare la quiebra; XIII- ordenará la citación del Ministerio Público y la comunicación por carta a las Haciendas Públicas Federales y todos los Estados y Municipios en los que el deudor tiene un establecimiento, para que tomen conocimiento de la quiebra". 
al juez a la recomposición del estado de conformidad (inciso IX), y también la posibilidad de que el juez determine, "cuándo comprende conveniente, la convocatoria de la asamblea general de acreedores para la constitución del Comité de Acreedores, teniendo la posibilidad de autorizar la manutención del Comité que eventualmente funciona en la recuperación judicial cuando se declare la quiebra"(inciso XII).

El art. 107, § 2, de la Ley n. 12.529/2011 (ley de competencia) autoriza al juez a designar a un interviniente para administrar la empresa en los casos en que haya una negativa a cumplir con una decisión emitida por el Consejo Administrativo de Defensa Económica (CADE).

Finalmente, con respecto al grado de reestructuración, todo dependerá de la gravedad del estado de disconformidad que dio lugar a la decisión estructural.

Para Edilson Vitorelli, "a medida que avanzaban los procesos de reforma estructural, se percibió que emitir órdenes al administrador, estableciendo objetivos genéricos, no era suficiente para alcanzar los resultados deseados. El juez o estaba involucrado en la vida diaria de la institución, cuidando las minucias de su funcionamiento, o tendría que conformarse con la ineficacia de su decisión" 38 .

Una de las características principales de la decisión estructural es la acentuada intervención judicial en la actividad de los sujetos involucrados en el proceso, sean privados o públicos ${ }^{39}$. Esto impone la necesidad de una revisión de varios conceptos como, en el caso de una decisión dirigida a la reestructuración de una entidad pública o la implementación de políticas públicas, la idea de imposibilidad de pronunciarse sobre el mérito administrativo por parte del Poder Judicial debido a la separación de poderes.

Según Sérgio Cruz Arenhart, "se necesita un sistema jurídico que sea lo suficientemente maduro para comprender la necesidad de revisar la idea de 'separación de poderes', percibiendo que no existe un Estado contemporáneo que conviva con la prohibición radical de la interferencia judicial en los actos de otras ramas del poder público" ${ }^{40}$.

Como consecuencia de esto, también es necesario repensar la idea de que el Poder Judicial no puede inmiscuirse en el análisis del llamado "mérito administrativo". Según Eduardo José da Fonseca Costa, "cuando el Poder Judicial condena al Estado a implementar una política hasta ahora inexistente, para complementar una política deficiente o para perfeccionar una política

38 LIMA, Edilson Vitorelli Diniz. O devido processo legal coletivo, cit., pp. 579-579.

39 Según Owen Fiss, la structural reform permite al Poder Judicial salir del aislamiento donde se encuentra cuando es llamado a resolver los litigios individuales o privados (la llamada dispute resolution), alcanzando al puesto del coparticipante del gobierno y parte integrante del sistema político (FISS, Owen. Two models of adjudication, cit., p. 764).

40 ARENHART, Sérgio Cruz. Decisões estruturais no direito processual civil brasileiro, cit., p. 397. También en ese sentido: VIOLIN, Jordão. Protagonismo judiciário e processo coletivo estrutural: o controle jurisdicional de decisões políticas. Salvador: JusPodivm, 2013, p. 146. 
ineficiente, el juez del caso termina inmiscuyéndose en un elemento del 'mérito' de la actividad administrativa e interfiriendo en el diseño institucional de la política pública prevista" ${ }^{41}$.

Para Marco Félix Jobim, "cuando el Poder Legislativo no consigue atribuir al pueblo nuevas leyes que puedan modificar ese ambiente o cuando el Poder Ejecutivo se queda inerte en su deber de administrar, es el Poder Judicial el que deberá intervenir, en ambos casos, a través de procesos individuales o colectivos. A ese fenómeno se da el nombre de activismo judicial, en oposición a la autocontención judicial, lo que en algunos casos puede traer beneficios y en otros perjuicios, siendo que lo que ahora se defiende es que un activismo judicial equilibrado a la tendencia del acierto es mayor que el error" 42 . Para el autor, "el activismo judicial utilizado de manera correcta puede aportar beneficios extremos al cumplimiento de las decisiones emanadas de las cortes superiores" ${ }^{43}$. A fin de cuentas, el activismo no pertenece al juez, sino a la ley y la Constitución (e incluso, muchas veces, de los estatutos normativos de las instituciones a ser reestructuradas) cuando se establece la finalidad que será alcanzada. El reconocimiento del problema estructural dirige todos los esfuerzos hacia la promoción de este estado ideal de cosas, que es un comando jurídico que adecúa la situación constatada por el ordenamiento jurídico.

Para asegurar que las providencias para implementar el estado ideal de cosas se cumplan en el tiempo, modo y grado deseados, el magistrado puede valerse de medidas ejecutivas típicas o atípicas (arts. 139, IV y 536, §1 ${ }^{\circ}, \mathrm{CPC}$ ), sobre las cuales hablaremos a continuación.

Los amplios poderes conferidos al juez, por las disposiciones del CPC, fundamentan una nueva forma de ver la efectividad de las decisiones judiciales. Por ello, es posible afirmar que el CPC — leído a partir de sus normas fundamentales-, es aplicable directamente a los procesos estructurales. Los demás textos normativos citados sirven para ejemplificar normativamente las conductas que pueden ser adoptadas por el juez, pero que no limitan su actuación.

También puede valerse del incentivo de la consensualidad para exhortar a los sujetos de cada parte del proceso para que, cooperativamente, inicien una negociación con relación al tiempo, modo y grado de la reestructuración que se implementará, celebrando reuniones y/o presentando propuestas en autos ${ }^{44}$.

(ii) En cuanto a la necesidad de crear un régimen de transición, hay una providencia importante que se debe adoptar, ya que el proceso estructural, en esencia, busca implementar una transición entre los estados de $\operatorname{cosas}^{45}$.

41 COSTA, Eduardo José da Fonseca. “A “execução negociada” de políticas públicas em juízo". Revista de Processo. São Paulo: RT, ano 37, v. 212, outubro/2012, p. 29.

42 JOBIM, Marco Félix. Medidas estruturantes, cit., p. 104.

43 JOBIM, Marco Félix. Medidas estruturantes, cit., p. 96.

44 VITORELLI, Edilson. O devido processo legal coletivo: dos direitos aos litígios coletivos. 2 ed. São Paulo: Thomson Reuters Brasil, 2019, p. 545.

45 Matheus Galdino, refiriéndose a la lección de Georg H. von Wright, menciona la expresión " $p T q$ ", donde " $p$ " corresponde al estado de cosas anterior (estado de disconformidad), " $q$ " corresponde 
El poder del órgano juzgador de crear una "justicia de transición” entre la situación anterior y de aquella que se pretende implementar sería, para algunos, implícito ${ }^{46}$, derivado del principio de protección de confianza ${ }^{47}$.

El art. 23 del Decreto Ley n. 4,657/1942, complementado por la Ley n. 13,655/2018, consagró expresamente ese deber, que pasa a ser un deber de cualquier órgano decisor (administrativo, jurisdiccional o controlador):

Art. 23. La decisión administrativa, controladora o judicial que establezca una nueva interpretación u orientación sobre una norma de contenido indeterminado, imponiendo un nuevo deber o un nuevo condicionamiento del derecho, deberá prever un régimen de transición que sea indispensable para que el nuevo deber o condicionamiento del derecho sea cumplido de modo proporcional, imparcial y eficiente, y sin perjuicio de los intereses generales.

(iii) Finalmente, con relación a la necesidad de una evaluación/fiscalización permanente de las medidas estructurales, puede ser útil el nombramiento de un gerente específico o un comité. También, es aplicable las técnicas previstas en la Ley n. 11.101/2005 (ley de quiebras) y la Ley n. 12.529/2011 (ley de defensa de la competencia), respecto a la posibilidad de que el juez designe a un administrador o interventor judicial ${ }^{48}$ para fiscalizar la implementación de la reforma proyectada.

Jordão Violin recuerda que los casos Holt v. Server, que ayudaron a implementar la reforma del sistema penitenciario del estado de Arkansas en los Estados Unidos, contribuyó significativamente, en sus palabras, a "popularizar la figura del special máster ou visiting committee, un auxiliar del juez ubicado dentro de la estructura que se pretende reformar. Su función es observar las prácticas diarias y evaluar el compromiso del demandado de cumplir con la decisión judicial. De ese modo, es posible conocer los hechos, desarrollar planes de acción y monitorear el cumplimiento de la decisión de manera más rápida y efectiva de lo que

al estado de cosas posterior (estado ideal cosas) y " $T$ " corresponde a la transición de un estado a otro. Para él, esta es la "expresión que, sin exagerar, puede considerarse la expresión general del objeto de los procesos estructurales" (GALDINO, Matheus Souza. "Breves reflexões sobre as consequências de uma compreensão teleológica dos fatos para a teoria do processo estrutural”. Processos estruturais. Sérgio Cruz Arenhart e Marco Félix Jobim (orgs.). 2 ed. Salvador: Juspodivm, 2019, p. 699-700).

46 CABRAL, Antonio do Passo. Juicio y preclusiones dinámicas. 2da ed. Salvador: Editora Juspodivm, 2013, p. 521, con amplias referencias. El autor concluye: "En efecto, muchas decisiones de quiebra de estabilidad deben ser acompañadas por reglas de transición para evitar una ruptura de las expectativas que pudieran haber sido creadas a favor del mantenimiento de la posición estable, y facilitar así una adaptación suave al nuevo reglamento. En ese sentido, la promulgación de reglas de transición no debe ser vista solo como un poder estatal, sino como un deber derivado de la cláusula del Estado de Derecho, con el correlato y respectivo derecho individual". (CABRAL, Antonio do Passo. Coisa julgada e preclusões dinâmicas, cit., p. 521.)

47 Sobre las reglas de transición creadas por el órgano jurisdiccional en el caso de la quiebra de estabilidad indispensable la lectura de CABRAL, Antonio do Passo. Coisa julgada e preclusões dinâmicas, cit., p. 520-544.

48 En el mismo sentido: VIOLIN, Jordão. "Holt v. Sarver e a reforma do sistema prisional no Arkansas”. Processos estruturais. Sérgio Cruz Arenhart e Marco Félix Jobim (org). 2 ed. Salvador: Juspodivm, 2019, p. 548. 
si estas tareas dependieran de la provocación y de la actividad probatoria de las partes" ${ }^{49}$.

Se pueden adoptar otras medidas, como la exigencia de que se entreguen informes periódicos, la designación de audiencias periódicas para la audiencia de testigos y la realización de inspecciones judiciales. Lo importante es percibir que esta segunda fase, que tiene como objetivo implementar la meta establecida en la decisión estructural, exige una amplia discusión y actividad probatoria.

Un ejemplo notable sobre el proceso estructural es la llamada ACP del Carbón ${ }^{50}$. En 1993, el Ministerio Público Federal presentó la acción civil pública n. 93.8000533-4 contra un grupo de empresas mineras y la Unión, en la Justicia Federal de Criciúma/SC, con el objetivo de obligar a los demandados a implementar un proyecto de recuperación ambiental del área degradada por la actividad minera.

La sentencia condenó a los demandados a presentar un proyecto de recuperación en seis meses y a implementarlo en tres años, mediante una multa coercitiva. La decisión final se convirtió en definitiva en el 2014, pero desde el 2000 se tramitaba el pedido de cumplimiento provisional formulado por el MPF.

La ejecución de la orden para la recuperación ambiental pasó, del 2000 al 2019, por cuatro fases distintas, contó con el nombramiento, por parte del juez, de un grupo de apoyo técnico para hacer el seguimiento y fiscalizar las providencias para la implementación de la meta, experimentó los beneficios de la consensualidad, se suscribió 19 acuerdos para implementar el plan de recuperación hasta 2020, y su ejecución puede ser acompañada por el internet, a través de un site desarrollado específicamente para publicar las providencias ya adoptadas para implementar el plan de recuperación ambiental establecido como meta ${ }^{51}$.

\subsubsection{Decisiones en cascada}

Otra característica destacable de las decisiones estructurales es que, a menudo, la decisión principal es seguida por otras innumerables que tienen como objetivo resolver los problemas derivados de la efectividad de las decisiones anteriores de modo que permiten la efectiva concretización del resultado establecido en la decisión principal —es lo que Sérgio Cruz Arenhart llama providencias en cascada ${ }^{52}$.

“Así, por ejemplo, es típico de las medidas estructurales la emisión de una primera decisión, que se limitará a establecer en líneas generales las directrices para la protección del derecho a ser tutelado, creando el núcleo de la

49 VIOLIN, Jordão. "Holt v. Sarver e a reforma do sistema prisional no Arkansas". Processos estruturais. Sérgio Cruz Arenhart e Marco Félix Jobim (orgs.). 2 ed. Salvador: Juspodivm, 2019, p. 527.

50 Ese caso ha sido bien detallado y explorado en ARENHART, Sérgio Cruz. "Processos estruturais no direito brasileiro: reflexões a partir do caso da ACP do carvão”. Revista de Processo Comparado. São Paulo: RT, jul/dez, 2015, n. 2, versión electrónica.

51 Disponible en: <http://acpcarvao.com.br/login/index.php> Acceso el 30/dic/2019.

52 ARENHART, Sérgio Cruz. "Decisões estruturais no direito processual civil brasileiro". Revista de Processo. São Paulo: RT, 2013, ano 38, v. 225, p. 400. 
posición jurisdiccional sobre el problema que se le plantea. Después de esta primera decisión, - generalmente más genérica, integral y casi 'principiológi$c a$ ', en el sentido de que tendrá como función principal establecer la 'primera impresión' sobre las necesidades de tutela jurisdiccional-, se requerirán otras decisiones para la solución de los problemas y cuestiones puntuales, que surgirán en la implementación de la 'decisión-núcleo', o para la especificación de alguna práctica debida". ${ }^{53}$

El art. 493 del CPC también coadyuva a comprender la disciplina de los procesos estructurales. Este dispositivo se ocupa de la tradicional ampliación del tema in decidendum y debe ser releído a la luz de la naturaleza flexible, indispensable para el proceso estructural.

$\mathrm{Al}$ autorizar e imponer que la decisión judicial se ajuste a la realidad actual de los hechos, el legislador le dice al juez que debe interpretar la demanda $-y$, además, las diversas expresiones de interés y postulaciones deducidas durante el proceso estructural-, de acuerdo con el escenario vigente al tiempo en que se emitió la decisión, flexibilizando la regla de congruencia ${ }^{54}$. La dinamicidad con que se altera el escenario fáctico de los litigios subyacentes a los procesos estructurales vuelve al art. 493 del CPC una herramienta fundamental para que el juez, en la etapa de efectivización de las decisiones estructurales, corrija el rumbo de la tutela ejecutiva de modo que contemple las necesidades actuales de los interesados.

Un ejemplo interesante es la acción civil pública n. 015073564.2008.8.26.0002, donde se instó al Municipio de São Paulo a resolver el problema del déficit de plazas en las guarderías municipales para niños de cero a tres años. Inicialmente, la decisión judicial estableció como meta (nuevo estado de cosas) la creación, para el 2016, de 150,000 vacantes. Para el año 2016, solo se habían creado 106.743 vacantes, lo que llevó a la conclusión de que 43.257 nuevas vacantes aún debían de crearse. Resulta que, después de un nuevo análisis del estado de cosas existente en el 2016, se concluyó que no se necesitarían más de 150,000 vacantes en total, sino 191,743 vacantes para el 2020. ${ }^{55}$. Este nuevo estado de cosas, distinto del establecido como meta cuando se emitió la decisión estructural, desde entonces, pasó a presidir la actuación del órgano jurisdiccional influenciado por la dinámica de los hechos y sus repercusiones en el proceso.

La segunda fase del proceso estructural está marcada por una sucesión de actos que tienen como objetivo, como se dijo, implementar la meta establecida. Pero nada impide que este objetivo sea revisado. El procedimiento finaliza solo cuando se entiende que se ha implementado el estado de cosas deseado.

53 ARENHART, Sérgio Cruz. "Decisões estruturais no direito processual civil brasileiro", cit., p. 400

${ }^{54}$ Ver el ejemplo de las acciones posesorias: se admite, en base al art. 554 del CPC, que el juez otorga al solicitante una protección posesoria adecuada a la realidad actual de los hechos, aunque diferente de la que fuera planteada cuando presentó la demanda.

55 El ejemplo fue citado por: GALDINO, Matheus Souza. "Breves reflexões sobre as consequências de uma compreensão teleológica dos fatos para a teoria do processo estrutural”. Processos estruturais. Sérgio Cruz Arenhart e Marco Félix Jobim (orgs.). 2 ed. Salvador: Juspodivm, 2019, p. 702. 


\subsection{Algunas técnicas de flexibilización del procedimiento en el proceso estructural}

\subsubsection{Atenuación de las reglas de congruencia objetiva externa $y$ de la estabilización objetiva de la demanda, con posibilidad de modificación del objeto}

Es necesario que se admita una cierta atenuación a la regla de congruencia objetiva externa (art. $141 \mathrm{c} / \mathrm{c}$ art. 492, CPC), exigiendo una correlación entre la decisión y la demanda que se resuelve, "de modo que se permite al magistrado algún margen de libertad para elegir la forma de actuación del derecho a ser tutelado" 56 .

En tales casos, es fundamental liberar al magistrado de algunas ataduras de los pedidos de las partes, ya que la lógica que rige los procesos estructurales no es la misma que inspira a los litigios no estructurales, donde el juez se enfrenta a tres caminos a seguir, a saber: aprobación, aprobación parcial o rechazo de la postulación.

La idea de los procesos estructurales es, como se observa, la de alcanzar una finalidad, mediante la ejecución estructurada de ciertas conductas. Pero sucede que no siempre es posible que la parte prevea todos los comportamientos que la parte contraria necesite adoptar o evitar para alcanzar esa finalidad. A menudo esto solo se puede apreciarse en el curso del proceso ${ }^{57}$.

Como consecuencia de esto, también es necesario atenuar la regla de estabilización objetiva de la demanda (art. 329, CPC), permitiendo, incluso, que el objeto sea modificado, siempre que se garantice la contradicción previa y sustancial.

Recordemos el ejemplo de la acción civil pública donde el Ministerio Público pretendía que el concesionario de la vía cumpliera estrictamente el contrato de concesión, segregando un vecindario que floreció alrededor de la vía. Constatándose que se trata de una pretensión contraria al interés de la comunidad que, supuestamente, es reemplazado en el polo activo del Ministerio Público, sería posible considerar la modificación del objeto para contemplar los intereses efectivos del título del derecho discutido.

La flexibilidad de la congruencia objetiva y de la estabilización de la demanda suponen que la interpretación del pedido (art. 322, § 2, CPC) toma en consideración la complejidad del litigio estructural. En una acción colectiva que se refiera, por ejemplo, a los miles de problemas relacionados con la ruptura de la presa de Samarco, en Minas Gerais en el 2015, el progreso del proce-

56 ARENHART, Sérgio Cruz. Decisões estruturais no direito processual civil brasileiro, cit., p. 398.

57 En ese sentido: ARENHART, Sérgio Cruz. "Processos estruturais no direito brasileiro: reflexões a partir do caso da ACP do carvão". Revista de Processo Comparado. São Paulo: RT, jul/dez, 2015, n. 2, versión electrónica. 
so, con la revelación de nuevas consecuencias del episodio, está transformando gradualmente el objeto litigioso y exigiendo nuevas medidas judiciales.

Es fundamental admitir, en los procesos estructurales, una cierta "plasticidad de la demanda" 58 .

De esa manera, basta que el demandante formule un pedido genérico para la conformación del estado de cosas sobre el cual se afirma la disconformidad -que, por ejemplo, el juez emita una providencia para: garantizar la vida, la integridad física y la dignidad de la población penitenciaria de un determinado establecimiento penitenciario; determinar si la empresa de una planta hidroeléctrica se implementa de acuerdo con la normativa vigente, determinada la adecuación del sistema de educación pública municipal; garantizar que los niños de determinada edad sean acogidos en las guarderías a tiempo completo, etcétera.

Un razonamiento similar se aplica al pedido que, habiendo sido formulado de manera estricta, puede extenderse desde el núcleo de la pretensión, que implica el reconocimiento del problema estructural. Una vez que es narrado el problema estructural e identificada la necesidad que será adecuada, se puede ejecutar por impulso del juez o incluso por consenso, respetando el contradictorio y la buena fe. Así, si el preso demanda la protección de su integridad física individual; si el propietario rural que se verá afectado por la represa demanda para proteger sus derechos o si surge una demanda individual que revela la falla en el sistema de educación pública para garantizar el acceso a la educación preescolar; estos mismos casos podrían tenerse en cuenta con el fin de adecuarlos para una tutela estructural.

El tiempo, el modo y el grado, el régimen de transición y la forma de evaluación y fiscalización deben ser limitados en un momento posterior, no requiriendo, necesariamente, ser objeto del pedido de la parte.

\subsubsection{Legitimidad democrática por la apertura del proceso a la participación de terceros}

El proceso estructural debe ser más abierto a la participación de terceros.

Debido a la complejidad y de la multipolaridad que normalmente caracterizan los procesos estructurales y de la potencialidad que las decisiones emitidas alcanzan a un número significativo de personas, es necesario pensar en nuevas formas de participación de los sujetos en el proceso, como la admisión del amici curiae y la convocatoria a audiencias públicas ${ }^{59}$. Las

\footnotetext{
58 La expresión es de Marcella Ferraro que defiende que la petición inicial, en los procesos estructurales, debe ser interpretada como un "esbozo de la demanda" (FERRARO, Marcella Pereira. Do processo bipolar a um processo coletivo-estrutural. Dissertação de Mestrado. Curitiba: Universidade Federal do Paraná (UFPR), 2015, p. 144 e 153).

59 En ese mismo sentido: GRINOVER, Ada Pellegrini. "Seoul Conference 2014 —Constitution and proceedings- The Judiciary as an Organ of Policital Control”. Revista de Processo. São Paulo: RT, 2015, v. 249 , p. 26.
} 
fórmulas tradicionales de intervención diseñadas para procesos individuales no son suficientes para garantizar una amplia participación en los procesos estructurales.

Marco Félix Jobim señala que "el hilo conductor de una teoría del litigio estructural pasa por la legitimidad democrática de determinadas decisiones judiciales" 60 . Una de las formas de garantizar esa legitimidad democrática de la decisión estructural es dar voz a los innumerables actores o grupos que pueden verse eventualmente afectados, independientemente de cuál sea el título bajo el que vengan a ingresar en el proceso.

Es posible considerar, como defiende Marcella Ferraro, una provocación específica, dirigida por el juez, a ciertos grupos o entidades, así como una llamada pública, a fin de que la participación sea, o pueda ser, lo más amplia posible $^{61}$. Esta convocatoria pública y la propia participación de los sujetos o grupos interesados pueden hacerse posible con la ayuda del internet, medios electrónicos y herramientas tecnológicas, con el objetivo de aumentar la publicidad y la transparencia ${ }^{62}$.

Como se observó anteriormente, la fase de implementación del plan de recuperación ambiental establecido en la llamada ACP del Carbón puede ser acompañada mediante el internet, a través del acceso al site especialmente desarrollado para propiciar, con transparencia, la fiscalización por cualquier interesado ${ }^{63}$. En Argentina, existe un Centro de Información Judicial, con acceso disponible, también, por el internet ${ }^{64}$, donde se puede recopilar noticias sobre las actividades de los tribunales del país, inclusive sobre la implementación de la decisión emitida en el llamado "caso Mendoza”, un proceso estructural dirigido a la descontaminación del río Riachuelo ${ }^{65}$.

La apertura del proceso a la participación de terceros no puede, sin embargo, convertirse en un obstáculo para la solución del problema estructural.

Como una forma de evitar que la amplia participación se convierta, en sí misma, en un problema, se pueden tomar medidas como la delimitación del centro de acción permitido a cada sujeto, con la identificación de los temas sobre los cuales se puede hablar o restringir su actuación a determinado acto

60 JOBIM, Marco Félix. "Reflexões sobre a necessidade de uma teoria dos litígios estruturais". Processos estruturais. Sérgio Cruz Arenhart e Marco Félix Jobim (org). 2 ed. Salvador: Juspodivm, 2019 , p. 648.

61 FERRARO, Marcella Pereira. Do processo bipolar a um processo coletivo-estrutural. Dissertação de Mestrado. Curitiba: Universidade Federal do Paraná (UFPR), 2015, p. 159-160.

62 MARÇAL, Felipe Barreto. "Repensando os mecanismos de ampliação do contraditório". Tecnologia jurídica \& Direito digital: II Congresso Internacional de Direito, Governo e Tecnologia. Ricardo Vieira de Carvalho Fernandes e Angelo Gamba Prata de Carvalho (coord). Belo Horizonte: Fórum, 2018, p. 459

${ }^{63}$ Disponible en: http://acpcarvao.com.br/login/index.php Acceso el 30/dic/2019.

64 Disponible en: https://www.cij.gov.ar/inicio.html Acceso el 30/dic/2019.

65 LAMÊGO, Gustavo. Técnicas de cooperação judiciária aplicadas a processos estruturais. Monografia de conclusão de curso de graduação em Direito. Salvador: Univerdade Federal da Bahia (UFBA), 2019 , p. 72. 
o fase del procedimiento ${ }^{66}$. Otra posibilidad es la elección de un "portavoz" con la atribución de hablar sobre determinado interés, evitando la proliferación de manifestaciones en el mismo sentido y reemplazándolas con una sola expresión concertada entre los titulares del interés ${ }^{67}$.

\subsubsection{Atipicidad de los medios probatorios}

Considerando que la discusión del tema, a menudo, implica una multiplicidad de cuestiones de hecho, es necesario, en estos casos, adoptar un modelo probatorio diferenciado, utilizando importantes medios de prueba atípicos (art. 369, CPC).

En el proceso donde se pretende, por ejemplo, establecer un plan para la adecuación y accesibilidad de vías, lugares públicos, edificios e instalaciones públicas en un lugar determinado, como una forma de concretización del derecho de tránsito de las personas con necesidades especiales, no se va a realizar una pericia en cada vía, lugar público, edificio o instalación pública. En el proceso donde se pretende salvaguardar la dignidad, la vida y la integridad física de la población carcelaria, mediante la adecuación de los edificios en los que estas personas se encuentran encarceladas, no siendo necesario inspeccionar cada celda de cada establecimiento penitenciario.

En tales casos, además de los medios de prueba típicos, se pueden y deben usarse otros medios de prueba, como la prueba por muestreo, la prueba estadística, la prueba prima facie, la prueba indiciaria, entre otros ${ }^{68}$.

\subsubsection{Atipicidad de las medidas ejecutivas. \\ Delegación de la actividad ejecutiva \\ para entidades de infraestructura especifica (EIE): Claims Resolution Facilities}

Si bien la efectividad de las decisiones emitidas en los procesos no estructurales, generalmente, se da de forma coercitiva, es común que la efectividad de la decisión estructural tenga lugar de manera dialéctica, "a partir de un

66 TEMER, Sofia Orberg. Participação no processo judicial: arranjos subjetivos e modalidades de atuação. Tese de doutorado. Rio de Janeiro: Universidade do Estado do Rio de Janeiro (UERJ), 2020, p. 280 .

67 TEMER, Sofia Orberg. Participação no processo judicial: arranjos subjetivos e modalidades de atuação, cit., p. 286-287.

68 Para Sérgio Cruz Arenhart, "la complejidad del caso, a menudo, vuelve inútil las "pruebas tradicionales', dado que se refieren a la demostración de hechos específicos, que ocurrieron en el pasado. Los litigios complejos, a su vez, debido a que generalmente carecen de una respuesta que se proyecte hacia el futuro, también demandará, muchas de las veces, un análisis de probabilidades futuras o, incluso al examinar el pasado, impondrán la evaluación de un plexo de situaciones, para evaluar adecuadamente la ocurrencia de cualquier infracción” (ARENHART, Sérgio Cruz. "A prova estatística e sua utilidade em litígios complexos”. Revista Direito e Práxis. Rio de Janeiro, vol. 10, n. 1, 2019, p. 663). 
amplio debate cuya única premisa consiste en tomar la controversia como el fruto de una estructura social a ser reformada" 69 .

En el derecho procesal brasileño, la base normativa para la ejecución de las decisiones estructurales, necesariamente atípicas, se deriva de la conjunción del art. 139, IV ${ }^{70}$, con el art. 536, § 1, ambos del CPC. Las disposiciones son cláusulas generales ejecutivas, de las cuales se deriva que el órgano juzgador posee el poder de promover la ejecución de sus decisiones mediante medidas atípicas.

Una de las técnicas posibles que se pueden utilizarse para cumplir con las decisiones estructurales es la creación de entidades de infraestructura específicas para la resolución de conflictos colectivos (claim resolution facilities) ${ }^{71}$, es decir, terceros responsables de implementar, total o parcialmente, la decisión judicial o la autocomposición, aunque sean de naturaleza privada o mixta.

Ejemplos: a) Fundación Renova, entidad creada a partir del acuerdo de ajuste de conducta suscrito entre las empresas Samarco, Valle del Río Doce y BHP Billiton con la Unión, los Estados de Minas Gerais y Espírito Santo y sus autarquías; el TAC suscrito en el 2002 entre la Compañía Energética de Minas Gerais-CEMIG, el MPF, el Estado de Minas Gerais y la Fundación Estatal del Medio Ambiente, con la intervención de otras entidades, para mitigar los impactos socioambientales resultantes de la implementación de la central hidroeléctrica de Irapé. El TAC previó medidas que dependerían del propio CEMIG, pero también estipulaba que la empresa debería suscribir un convenio con la Empresa de Asistencia Técnica y Extensión Rural de Minas GeraisEMATER, que sería responsable de proporcionar asistencia técnica y ejecutar muchas otras medidas, como las de reasentamiento de los afectados. Además, se previó destinar "fondos de mantenimiento temporal", que serán administrados por las asociaciones creadas en cada reasentamiento, de acuerdo con un plan predefinido; b) proyectos realizados por grupos de privados a partir de la provocación de las entidades públicas para resolver cuestiones como los deslizamientos, inundaciones y desalojos en razón de las lluvias en Río de

69 VIOLIN, Jordão. Protagonismo judiciário e processo coletivo estrutural, cit., p. 151. Eduardo José da Fonseca Costa utiliza las expresiones "ejecución negociada" y "ejecución cooperativa compleja" para describir la participación de los sujetos en la efectivización de las decisiones cuyo objeto es efectivar las políticas públicas (COSTA, Eduardo José da Fonseca. A “execução negociada” de políticas públicas em juízo, cit., pp. 41-42). Para él, "el día a día de la práctica forense ha demostrado, de ese modo, que la ejecución forzada, no es la forma más eficiente de implar en un proceso determinada política pública" ( ibidem, p. 35).

70 JOBIM, Marco Felix. "A previsão das medidas estruturantes no artigo 139, IV, do novo Código de Processo Civil brasileiro”. Repercussões do novo CPC - processo coletivo. Hermes Zaneti Jr. (coord.). Salvador: Editora Juspodivm, 2016, p. 230-232.

71 A partir de aquí, se tiene la versión modificada, resumida y simplificada del texto publicado por uno de los autores del volumen 4 de este Curso juntamente con Antonio Cabral: CABRAL, Antonio; ZANETI JR., Hermes. "Entidades de infraestrutura específica para a resolução de conflitos coletivos: as claims resolution facilities e sua aplicabilidade no Brasil”. Revista de Processo. São Paulo: RT, 2019, v. 287 . 
Janeiro; c) la contratación por parte del grupo Oi, en el curso del proceso de recuperación judicial, de una fundación para crear una plataforma digital a fin de viabilizar la mediación con miles de acreedores en todo el país ${ }^{72}$.

Esta práctica no es nueva en el Derecho comparado. En los Estados Unidos, durante al menos dos décadas, ha sido frecuente la constitución de las llamadas claims resolutions facilities.

Ellas tienen un potencial transformador en la práctica de la tutela de los problemas estructurales y significan una nueva forma de pensar acerca de los diferentes institutos del Derecho procesal. Son una nueva modalidad de participación de terceros en el proceso; puede estar constituido por convenciones procesales (arts. 190 y 200 del CPC) o por delegación de funciones jurisdiccionales por actos conjuntos (art. 69 del CPC), dos temas que están en las últimas fronteras de la investigación sobre las fuentes de las normas procesales y de las funciones de la jurisdicción en el mundo contemporáneo.

También representan una nueva forma de gestión y organización del proceso y pueden resultar especialmente útiles para los litigios estructurantes. Incluso, pueden considerarse un tipo de medida inductiva y de apoyo para obtener la implementación, el cumplimiento o la satisfacción de los derechos colectivos (arts. 139, IV, 297 y $536 § 1^{\circ}, \mathrm{CPC}$ ). Quizás debido a todo esto, las claims resolution facilities causan cierta extrañeza.

\subsubsection{Atipicidad de la cooperación judicial}

La cooperación judicial nacional está organizada a partir de la premisa de que los actos e instrumentos de cooperación son atípicos.

Esto significa que la interacción entre los órganos judiciales, para que uno coopere con el otro para la prestación del servicio jurisdiccional, puede realizarse de varias maneras.

Los procesos estructurales son ambientes extremadamente propicios para el uso de las técnicas de cooperación judicial. Es poco probable que los procesos estructurales complejos y multipolares tengan éxito sin el manejo de este instrumento ${ }^{73}$.

Dos ejemplos son útiles.

a) La técnica de centralización de procesos repetitivos (art. 69, § 2, VI, CPC) es bienvenida en los procesos estructurales.

72 Se trata de la plataforma según la recuperación judicial del Grupo Oi, creada para la mediación de los acreedores cuyos créditos aún son ilíquidos, así como para recibir incidentes de habilitación e impugnación. Disponible en: https://www.credor.oi.com.br Acceso el 30/dic/2019.

${ }_{73}$ Percibirán el punto TOSTA, André Ribeiro; MARÇAL, Felipe Barreto. "Gerenciamento processual adequado de demandas formalmente individuais a partir de uma visão estruturante: o reforço proporcionado pelo art. 21 da LINDB”. Processos estruturais. Sérgio Cruz Arenhart e Marco Félix Jobim (orgs.). 2a ed. Salvador: Juspodivm, 2019, p.195-196. 
Se sabe que, en un proceso estructural, se fijan las metas que serán alcanzadas a mediano y largo plazo. Sucede que, en determinados contextos, un litigio estructural puede dar lugar a la presentación de numerosas demandas individuales que, incluso, pueden interferir en la ejecución de los planes establecidos en el proceso estructural. Por otro lado, estas demandas individuales no-estructurales no tienen la capacidad de poner fin a los litigios estructurales. Por esta razón, la centralización de estos procesos puede ser el medio idóneo para viabilizar la implementación de las metas establecidas en los procesos estructurales, ya que la decisión de los procesos no-estructurales relacionados con la cuestión no sería realizada sin desconocer el plan establecido en el proceso estructural ${ }^{74}$. Y más: es un medio para garantizar la isonomía ${ }^{75}$, ya que evita el trato diferente de quien buscan al Poder Judicial, con relación a quien pretenda la satisfacción de su derecho por otros medios.

b) La cooperación judicial puede tener lugar entre órganos que están relacionados mediante un vínculo jerárquico. En tales casos, la cooperación judicial puede ocurrir por delegación de un poder del órgano jerárquicamente superior al órgano vinculado a él.

La cooperación por delegación generalmente se realiza mediante el instrumento de la carta de orden y para la práctica de actos de instrucción (art. 972, CPC, por ejemplo), comunicación o ejecución. El STF está autorizado, por ejemplo, a delegar atribuciones para practicar actos procesales relacionados con la ejecución de sus sentencias (art. 102, I, “m”, CF/1988). Esta delegación debe hacerse a jueces de primera instancia ${ }^{76} \mathrm{y}$ puede referirse a la práctica de actos ejecutivos.

A partir del CPC del 2015, la delegación puede ocurrir por cualquier instrumento y para practicar cualquier acto de cooperación, no solo actos de instrucción, de comunicación o ejecución.

Incluso, es posible concebir la delegación para la práctica de un número indeterminado de actos.

El caso de la ADPF n. 347, en el que el STF fue llamado a decidir sobre el estado de las cárceles brasileñas, puede ser un buen ejemplo. La solución del

74 LAMÊGO, Gustavo Cavalcanti. LAMÊGO, Gustavo Cavalcanti. Técnicas de cooperação judiciária aplicadas a processos estruturais. 2019. Monografia (Graduação). Universidade Federal da Bahia, Salvador, 2019 p. 76-79; MARÇAL, Felipe Barreto. "Deveres Cooperativos do Magistrado no Processo Estruturante: da cooperação com as partes à cooperação com outros órgãos (judiciários ou extrajudiciários), por meio de atribuição de competências e delegações". Civil Procedure Review, v. 10, p. 77-99, 2019.

75 GALDINO, Matheus, Souza. Elementos para uma compreensão tipológica dos processos estruturais. Dissertação (Mestrado - Direito). Orientador: Prof. Dr. Fredie Didier Jr. Salvador: Universidade Federal da Bahia, 2019, p. 122; LAMÊGO, Gustavo Cavalcanti. Técnicas de cooperação judiciária aplicadas a processos estruturais, cit., p. 78; TOSTA, André Ribeiro; MARÇAL, Felipe Barreto. "Gerenciamento processual adequado de demandas formalmente individuais a partir de uma visão estruturante: o reforço proporcionado pelo art. 21 da LINDB". Processos Estruturais. Sérgio Cruz Arenhart e Marco Félix Jobim (org.). 2a ed., rev., atual. e ampl., Salvador: Juspodivm, 2019, p. 197-200.

76 DINAMARCO, Cândido Rangel. Instituições de Direito Processual Civil. São Paulo: Malheiros Ed., 2004, t. 4, p. 101; ASSIS, Araken de. Cumprimento da sentença. Rio de Janeiro: Forense, 2006, p. 183. 
problema implicará un cambio estructural en el sistema penitenciario brasileño. El STF puede delegar la función de concretizar su decisión a los jueces de ejecución penal, estableciendo las directrices generales y preservando el poder de fiscalizar las medidas, para no perder el control - a fin de cuentas, la delegación de la ejecución de sus decisiones está constitucionalmente autorizada (art. 102, I, “m”, CF/1988) ${ }^{77}$.

\subsection{Adopción del procedimiento común del CPC, con tránsito de técnicas}

El procedimiento común del CPC puede servir adecuadamente como un circuito-base para el desarrollo del proceso estructural. Esto se debe porque el CPC utilizó un procedimiento estándar muy flexible, caracterizado, entre otras cosas, por ${ }^{78}$ : (i) prever, en varios dispositivos la posibilidad de adaptarse a las peculiaridades del caso concreto (p. ej., arts. $7^{\circ}, 139$, IV, 297, 300 y 536, $\S 1^{\circ}, \mathrm{CPC}$ ); (ii) admitir la concesión de una tutela provisional, cautelar o satisfactiva, fundada en la urgencia o en la evidencia, preliminarmente o durante el proceso; (iii) permitir el fraccionamiento de la resolución de los méritos de la causa (art. 354, párrafo único, y 356, CPC); (iv) admitir la cooperación judicial (arts. 67 al 69, CPC); (v) permitir la celebración de negocios jurídicos procesales (art. 190, CPC); (vi) autorizar la adopción, por parte del juez, de las medidas ejecutivas atípicas (art. 139, IV y 536, §1 ${ }^{\circ}, \mathrm{CPC}$ ).

Pero eso no es todo.

El art. 327 del CPC admite la "acumulación, en un solo proceso, contra el mismo demandado, de varios pedidos, aunque entre ellos no haya conexión". El párrafo $§ 2^{\circ}$ de esta disposición prescribe que "cuando, para cada pedido, corresponda un tipo diferente de procedimiento, se permitirá la acumulación si el demandante emplea el procedimiento común, sin perjuicio del uso de las técnicas procesales diferenciadas previstas en los procedimientos especiales a los que se sujetan uno o más pedidos acumulados, que no son incompatibles con las disposiciones del procedimiento común".

Como puede verse, la parte final del §2 del art. 327 admite que el procedimiento común se adapte para que en él se inserte y utilice la técnica procesal diferenciada prevista en el procedimiento especial. La doctrina ha percibido en dicha disposición una especie de "portal" que permite el llamado "tránsito de técnicas" de los procedimientos especiales hacia el procedimiento común, $\mathrm{y}$ viceversa.

77 SARAIVA, Carolina Barros. "Condução dialógica dos processos estruturais no Supremo Tribunal Federal”. In: ARENHART, Sérgio Cruz; e JOBIM, Marco Félix. (org.). Processos Estruturais. 2. ed. rev., atual. e ampl. Salvador: Juspodivm, 2019, p. 239-240; LAMÊGO, Gustavo Cavalcanti. Técnicas de cooperação judiciária aplicadas a processos estruturais, cit., p. 67-69.

78 DIDIER JR., Fredie; CABRAL, Antonio do Passo; CUNHA, Leonardo Carneiro da. Por uma nova teoria dos procedimentos especiais. Salvador: Juspodivm, 2018, p. 65-67. 
El $\S 2^{\circ}$ del art. 327 del CPC es, en resumen, una cláusula general de flexibilización procedimental. Es posible importar hacia el procedimiento común técnicas especiales de tutela jurisdiccional, pero también es posible lo contrario, es decir, importar hacia el procedimiento especial la regla del procedimiento común, a fin de concretizar las normas fundamentales. En ese sentido, es posible que el juez determine, por ejemplo, la presentación de la réplica del requirente en el mandato de seguridad, aplicando a dicho procedimiento de acción constitucional, lo dispuesto en los arts. 351 y 352 del CPC, reforzando, de ese modo, el contradictorio (art. 9 y 10 del CPC), así como la posibilidad de corregir los vicios procesales, en concreción al principio de primacía de la decisión de mérito (art. 4, CPC).

Pero es necesario dar un paso más. También es posible defender que una técnica especial se aplique a otro procedimiento especial, siempre que sea compatible con ella. A partir de estas disposiciones del CPC, se puede concluir que existe un tipo de libre tránsito de las técnicas diferenciadas entre procedimientos, que solo requieren compatibilidad. ${ }^{79}$

El art. 1049 del CPC confirma este entendimiento.

En su caput, prescribe que "siempre que la ley se refiera al procedimiento previsto en la ley procesal sin especificarlo, se observará el procedimiento común previsto en este Código". En el único párrafo, establece que "en el caso de que la ley se refiera al procedimiento sumario, se observará el procedimiento común previsto en este Código, con las modificaciones previstas en la propia ley especial, si hubiese".

El parágrafo único del art. 1049 está en consonancia con el §2 del art. 327 del CPC, que permite que las técnicas de los procedimientos especiales que no sean incompatibles con el procedimiento común se incorporen a este ${ }^{80}$.

Las técnicas de flexibilización previstas expresamente en ciertos dispositivos, la consensualidad y la posibilidad de utilizar técnicas de procesales previstas en procedimientos especiales hacen que el procedimiento común del CPC sea un circuito propicio para la tramitación de los procesos estructurales.

\section{CONCLUSIÓN}

Como conclusión, creemos que es posible establecer un concepto sobre el proceso estructural a partir del concepto de problema estructural, entendiendo así el estado de disconformidad estructurada — una situación de ilicitud continua y permanente o una situación de disconformidad, aunque no exactamente ilícita, en el sentido de que es una situación que no corresponde al estado de cosas considerado ideal.

79 DIDIER JR., Fredie; CABRAL, Antonio do Passo; CUNHA, Leonardo Carneiro da. Por uma nova teoria dos procedimentos especiais. Salvador: Juspodivm, 2018, p. 73.

80 DIDIER JR., Fredie; CABRAL, Antonio do Passo; CUNHA, Leonardo Carneiro da. Por uma nova teoria dos procedimentos especiais. Salvador: Juspodivm, 2018, p. 75-76. 
El proceso estructural es aquel donde se desarrolla un litigio estructural, basado en un problema estructural, y donde se pretende cambiar ese estado de disconformidad, reemplazándolo por un estado de cosas ideal.

El proceso estructural se caracteriza por: (i) basarse en la discusión de un problema estructural, un estado de cosas ilícito, un estado de disconformidad, o cualquier otro nombre que se quiera utilizar para designar una situación de disconformidad estructurada; (ii) buscar una transición de ese estado de disconformidad a un estado ideal de cosas (en consecuencia, una reestructuración), eliminando la situación de disconformidad, mediante una decisión de implementación escalonada; (iii) desarrollarse en un procedimiento bifásico, que incluye el reconocimiento y la definición del problema estructural y establece el programa o proyecto de reestructuración que se seguirá; (iv) desarrollar en un procedimiento marcado por su flexibilidad intrínseca, con la posibilidad de adoptar formas atípicas de intervención de terceros y medidas ejecutivas, de alterar el objeto litigioso, de utilizar mecanismos de cooperación judicial; y (v) la consensualidad, que abarque incluso la adaptación del proceso (art. 190, CPC).

Además, el proceso estructural también tiene algunas características típicas, pero no esenciales: multipolaridad, colectividad y complejidad.

No hay forma de establecer previamente qué procedimiento debe observarse en el proceso estructural, pero, en cualquier situación, este procedimiento debe ser bifásico, como ocurre en el proceso de quiebra. La primera fase del proceso estructural debe estar dedicada a la verificación de la existencia de un problema estructural y su propósito es, una vez que se verifica el problema, establecer la meta a alcanzar —el estado ideal de las cosas-, terminando con la emisión de la llamada decisión estructural. La segunda fase del proceso estructural se inicia con la implementación de las medidas necesarias para alcanzar la meta establecida en la decisión estructural.

El procedimiento de dos fases del proceso estructural está marcado por su flexibilidad intrínseca y por la consensualidad.

La flexibilidad del proceso estructural debe garantizarse mediante la aplicación de técnicas procesales flexibles, como la que atenúa las reglas de congruencia objetiva y la estabilización objetiva de la demanda, la ampliación del régimen de participación en el proceso, la atipicidad de los medios de prueba (art. 369, CPC), la atipicidad de las medidas ejecutivas (art. 139, IV y art. 536, § 1, CPC) y la atipicidad de los instrumentos de cooperación judicial (art. 69, CPC).

El procedimiento común del CPC puede servir adecuadamente como un circuito-base para el desarrollo del proceso estructural, debido a las técnicas flexibles previstas en el ordenamiento y la posibilidad de un tránsito de técnicas entre el procedimiento común y los procedimientos especiales previstos en el propio CPC y en el legislación especial. 
Estas son las principales propuestas presentadas en este artículo para un tema que aún está en desarrollo. Esperamos que ellas puedan estimular y ampliar el debate.

\section{REFERENCIAS BIBLIOGRÁFICAS}

ARENHART, Sérgio Cruz. "A prova estatística e sua utilidade em litígios complexos". Revista Direito e Práxis. Rio de Janeiro, vol. 10, n. 1, 2019.

—. "Decisões estruturais no direito processual civil brasileiro". Revista de Processo. São Paulo: RT, 2013, ano 38, v. 225

—. "Processos estruturais no direito brasileiro: reflexões a partir do caso da ACP do carvão". Revista de Processo Comparado. São Paulo: RT, jul/dez, 2015, n. 2, versão eletrônica.

—. "Processo multipolar, participação e representação de interesses concorrentes". Processos estruturais. Sérgio Cruz Arenhart e Marco Félix Jobim (org). 2 ed. Salvador: Juspodivm, 2019.

ASSIS, Araken de. Cumprimento da sentença. Rio de Janeiro: Forense, 2006.

BATISTA, Felipe Vieira. A recuperação judicial como processo coletivo. Dissertação de Mestrado. Salvador: Universidade Federal da Bahia (UFBA), 2017.

CABRAL, Antonio do Passo. Coisa julgada e preclusões dinâmicas. $2^{\mathrm{a}}$ ed. Salvador: Editora Juspodivm, 2013.

CABRAL, Antonio; ZANETI JR., Hermes. "Entidades de infraestrutura específica para a resolução de conflitos coletivos: as claims resolution facilities e sua aplicabilidade no Brasil". Revista de Processo. São Paulo: RT, 2019, v. 287.

COSTA, Eduardo José da Fonseca. «A "execução negociada” de políticas públicas em juízo». Revista de Processo. São Paulo: RT, ano 37, v. 212, outubro/2012.

DIDIER JR., Fredie; CABRAL, Antonio do Passo; CUNHA, Leonardo Carneiro da. Por uma nova teoria dos procedimentos especiais. Salvador: Juspodivm, 2018.

DIDIER JR., Fredie; ZANETI JR., Hermes. «Comentários ao art. 333 do CPC-2015». Breves comentários ao novo Código de Processo Civil. Teresa Arruda Alvim Wambier, Fredie Didier Jr., Eduardo Talamini e Bruno Dantas (coord). 3 ed. São Paulo: RT, 2016.

—. "Conceito de processo jurisdicional coletivo". Revista de Processo. São Paulo: RT, 2014, v. 229.

DIDIER JR., Fredie; ZANETI JR., Hermes; OLIVEIRA, Rafael Alexandria de. "Notas sobre as decisões estruturantes". Processos estruturais. Sérgio Cruz Arenhart e Marco Félix Jobim (org). 2 ed. Salvador: Juspodivm, 2019.

DINAMARCO, Cândido Rangel. «Instituições de Direito Processual Civil». São Paulo: Malheiros Ed., 2004, t. 4.

FERRARO, Marcella Pereira. Do processo bipolar a um processo coletivo-estrutural. Dissertação de Mestrado. Curitiba: Universidade Federal do Paraná (UFPR), 2015.

FISS, Owen. "Two models of adjudication”. In: Didier JR. Fredie, Jordão, Eduardo Ferreira (coord.). Teoria do processo: panorama doutrinário mundial. Salvador: Juspodivm, 2008.

GALDINO, Matheus Souza. "Breves reflexões sobre as consequências de uma compreensão teleológica dos fatos para a teoria do processo estrutural". Processos estruturais. Sérgio Cruz Arenhart e Marco Félix Jobim (org). 2 ed. Salvador: Juspodivm, 2019.

- Elementos para uma compreensão tipológica dos processos estruturais. Dissertação de Mestrado. Salvador: Universidade Federal da Bahia (UFBA), 2019. 
GRINOVER, Ada Pellegrini. "Seoul Conference 2014 - Constitution and proceedings - The Judiciary as an Organ of Policital Control". Revista de Processo. São Paulo: RT, 2015, v. 249.

JOBIM, Marco Felix. "A previsão das medidas estruturantes no artigo 139, IV, do novo Código de Processo Civil brasileiro”. Repercussões do novo CPC-processo coletivo. Hermes Zaneti Jr. (coord.). Salvador: Editora Juspodivm, 2016.

- Medidas estruturantes: da Suprema Corte Estadunidense ao Supremo Tribunal Federal. Porto Alegre: Livraria do Advogado Editora, 2013.

LAMÊGO, Gustavo. Técnicas de cooperação judiciária aplicadas a processos estruturais. Monografia de conclusão de curso de graduação em Direito. Salvador: Univerdade Federal da Bahia (UFBA), 2019.

LIMA, Edilson Vitorelli Diniz. O devido processo legal coletivo: representação, participação e efetividade da tutela jurisdicional. Tese de doutorado apresentada à Faculdade de Direito da Universidade Federal do Paraná (UFPR). Curitiba, 2015.

—. "Tipologia dos litígios transindividuais: um novo ponto de partida para a tutela coletiva". Repercussões do novo CPC-processo coletivo. Hermes Zaneti Jr. (coord.). Salvador: Editora Jus Podivm, 2015.

MARÇAL, Felipe Barreto. "Repensando os mecanismos de ampliação do contraditório". Tecnologia jurídica \& Direito digital: II Congresso Internacional de Direito, Governo e Tecnologia. Ricardo Vieira de Carvalho Fernandes e Angelo Gamba Prata de Carvalho (coord). Belo Horizonte: Fórum, 2018.

SARAIVA, Carolina Barros. "Condução dialógica dos processos estruturais no Supremo Tribunal Federal”. Processos estruturais. Sérgio Cruz Arenhart e Marco Félix Jobim (org). 2 ed. Salvador: Juspodivm, 2019.

TEMER, Sofia Orberg. Participação no processo judicial: arranjos subjetivos e modalidades de atuação. Tese de doutorado. Rio de Janeiro: Universidade do Estado do Rio de Janeiro (UERJ), 2020.

TOSTA, André Ribeiro; MARÇAL, Felipe Barreto. "Gerenciamento processual adequado de demandas formalmente individuais a partir de uma visão estruturante: o reforço proporcionado pelo art. 21 da LINDB”. Processos estruturais. Sérgio Cruz Arenhart e Marco Félix Jobim (org). 2 ed. Salvador: Juspodivm, 2019.

VIOLIN, Jordão. "Holt v. Sarver e a reforma do sistema prisional no Arkansas». Processos estruturais. Sérgio Cruz Arenhart e Marco Félix Jobim (org). 2 ed. Salvador: Juspodivm, 2019.

VITORELLI, Edilson. "Levando os conceitos a sério: processo estrutural, processo coletivo, processo estratégico e suas diferenças". Revista de Processo. São Paulo: Thomson Reuters, outubro/2018, v. 284, p. 333-369.

—. "Litígios estruturais: decisão e implementação de mudanças socialmente relevantes pela via processual". Processos estruturais. Sérgio Cruz Arenhart e Marco Félix Jobim (org). 2 ed. Salvador: Juspodivm, 2019.

-. O devido processo legal coletivo: dos direitos aos litígios coletivos. 2 ed. São Paulo: Thomson Reuters Brasil, 2019.

WATANABE, Kazuo. "Relação entre demanda coletiva e demandas individuais». Revista de Processo. São Paulo: RT, 2006, v. 139. 